\title{
Front line defenders of the ecological niche! Screening the structural diversity of peptaibiotics from saprotrophic and fungicolous Trichoderma/Hypocrea species
}

\author{
Christian R. Röhrich • Walter M. Jaklitsch • Hermann Voglmayr • Anita Iversen • \\ Andreas Vilcinskas • Kristian Fog Nielsen • Ulf Thrane • Hans von Döhren • \\ Hans Brückner • Thomas Degenkolb
}

Received: 16 October 2013 / Accepted: 21 December 2013 /Published online: 9 April 2014

(C) The Author(s) 2014. This article is published with open access at Springerlink.com

\begin{abstract}
Approximately 950 individual sequences of nonribosomally biosynthesised peptides are produced by the genus Trichoderma/Hypocrea that belong to a perpetually growing class of mostly linear antibiotic oligopeptides, which are rich in the non-proteinogenic $\alpha$-aminoisobutyric acid (Aib). Thus, they are comprehensively named peptaibiotics. Notably, peptaibiotics represent ca. $80 \%$ of the total inventory of secondary metabolites currently known from Trichoderma/Hypocrea. Their unique membrane-modifying bioactivity results from amphipathicity and helicity, thus making them ideal candidates in assisting both
\end{abstract}

Dedicated to Gary J. Samuels on the occasion of his $70^{\text {th }}$ birthday.

Electronic supplementary material The online version of this article (doi:10.1007/s13225-013-0276-z) contains supplementary material, which is available to authorized users.

\section{R. Röhrich · A. Vilcinskas}

Bioresources Project Group, Fraunhofer Institute for Molecular

Biology and Applied Ecology (IME), Winchesterstrasse 2,

35394 Giessen, Germany

W. M. Jaklitsch $\cdot$ H. Voglmayr

Department of Systematic and Evolutionary Botany, Faculty Centre

of Biodiversity, University of Vienna, Rennweg 14,

1030 Vienna, Austria

A. Iversen · K. F. Nielsen • U. Thrane

Department of Systems Biology, Technical University of Denmark, Søltofts Plads, Building 221, 2800 Kgs. Lyngby, Denmark

H. von Döhren

Biochemistry and Molecular Biology OE 2, Institute of Chemistry, Technical University of Berlin, Franklinstrasse 29,

10587 Berlin, Germany

\section{H. Brückner}

Interdisciplinary Research Centre for BioSystems, Land Use and Nutrition (IFZ), Department of Food Sciences, Institute of Nutritional Science, University of Giessen, Heinrich-Buff-Ring 26-32,

35392 Giessen, Germany colonisation and defence of the natural habitats by their fungal producers. Despite this, reports on the in vivo-detection of peptaibiotics have scarcely been published in the past. In order to evaluate the significance of peptaibiotic production for a broader range of potential producers, we screened nine specimens belonging to seven hitherto uninvestigated fungicolous or saprotrophic Trichoderma/Hypocrea species by liquid chromatography coupled to electrospray high resolution mass spectrometry. Sequences of peptaibiotics found were independently confirmed by analysing the peptaibiome of pure agar cultures

A. Vilcinskas $\cdot$ T. Degenkolb $(\bowtie)$ Interdisciplinary Research Centre for BioSystems, Land Use and Nutrition (IFZ), Department of Applied Entomology, Institute of Phytopathology and Applied Zoology (IPAZ), University of Giessen, Heinrich-Buff-Ring 26-32, 35392 Giessen, Germany e-mail: thomas.degenkolb@ernaehrung.uni-giessen.de

Present Address:

C. R. Röhrich

AB SCIEX Germany GmbH, Landwehrstrasse 54, 64293 Darmstadt, Germany

Present Address:

A. Iversen

Danish Emergency Management Agency, Universitetsparken 2,

2100 Copenhagen, Denmark 
obtained by single-ascospore isolation from the specimens. Of the nine species examined, five were screened positive for peptaibiotics. A total of 78 peptaibiotics were sequenced, 56 (= $72 \%$ ) of which are new. Notably, dihydroxyphenylalaninol and $O$-prenylated tyrosinol, two $C$-terminal residues, which have not been reported for peptaibiotics before, were found as well as new and recurrent sequences carrying the recently described tyrosinol residue at their $C$-terminus. The majority of peptaibiotics sequenced are 18- or 19-residue peptaibols. Structural homologies with 'classical representatives' of subfamily 1 (SF1)peptaibiotics argue for the formation of transmembrane ion channels, which are prone to facilitate the producer capture and defence of its substratum.

Keywords HPLC/QTOF-ESI-HRMS · Metabolite profiling • Peptaibiotics $\cdot$ Peptaibols $\cdot$ Aib peptides $\cdot$ Trichoderma .

Hypocrea

\section{Introduction}

Currently, the fungal genus Trichoderma/Hypocrea ${ }^{1}$ comprises more than 200 validly described species, which have been recognised by molecular phylogenetic analysis (Atanasova et al. 2013). This high taxonomic diversity in Trichoderma/ Hypocrea is not only reflected in a permanently increasing number of species (Jaklitsch 2009, 2011; Jaklitsch and Voglmayr 2012; Jaklitsch et al. 2012, 2013; Chaverri et al. 2011; Samuels and Ismaiel 2011, Samuels et al. 2012a,b; Kim et al. 2012, 2013; Yamaguchi et al. 2012; Li et al. 2013; LópezQuintero et al. 2013, Yabuki et al. 2014), but also in a fastgrowing number of secondary metabolites of remarkable structural diversity. The latter include low-molecular-weight compounds such as pyrones (Jeleń et al. 2013), butenolides, terpenes, and steroids, but also $N$-heterocyclic compounds and isocyanides. In addition to these relatively nonpolar and often partly volatile compounds, an impressive inventory of nonvolatile compounds, comprising some alkaloids and an imposing number of peptide antibiotics, is produced. Reino et al. (2008) reviewed 186 compounds; however, peptaibiotics (see below) were treated only marginally and incomprehensively. As of August 2013, a total of 501 entries are recorded for Trichoderma (461) and Hypocrea (40) in AntiBase, more than 300 of which are N-containing, including less than 100 in the range of 50-800 Da (Laatsch 2013).

\footnotetext{
${ }^{1}$ Authors are aware of the drastic change of the ICBN (International Code of Botanical Nomenclature), which has been adopted at the IBC in Melbourne in July 2011 (Gams et al. 2012; Rossman et al. 2013). However, all strains used in this study were deposited at CBS in July/August 2012, and practical work for this study was finished in December 2012. For reasons of conformity with recently published contributions in the field of peptaibiotics, dual nomenclature is retained in this chemically focussed article.
}

Considering recent publications in this field, which have not yet been included into AntiBase 2013 (Table 1), an estimate of 225 to 250 non-peptaibiotic secondary metabolites from Trichoderma/Hypocrea seems appropriate. However, the overwhelming majority of secondary metabolites obtained from this genus so far belong to a perpetually growing family of non-ribosomally biosynthesised, linear or, in a few cases, cyclic peptide antibiotics of exclusively fungal origin, comprehensively named peptaibiotics:

According to the definition, the members of this peptide family show, besides proteinogenic amino acids, $i$ ) a relatively high content of the marker $\alpha$-aminoisobutyric acid (Aib), which is often accompanied by other $\alpha, \alpha$-dialkyl $\alpha$-amino acids such as D- and/or L-isovaline (Iva) or, occasionally, $\alpha$-ethylnorvaline (EtNva), or 1-aminocyclopropane-1-carboxylic acid (Acc); ii) have a molecular weight between 500 and 2,100 Da, thus containing 4-21 residues; iii) are characterised by the presence of other non-proteinogenic amino acids and/or lipoamino acids; iv) possess an acylated $N$-terminus, and $v$ ) in the case of linear peptides, have a $C$-terminal residue that most frequently consists of an amide-bonded $\beta$-amino alcohol, thus defining the largest subfamily of peptaibiotics, named peptaibols. Alternatively, the $C$-terminus might also be a polyamine, amide, free amino acid, 2,5-diketopiperazine, or a sugar alcohol (Degenkolb and Brückner 2008; Stoppacher et al. 2013).

Of the approximately 1,250 to 1,300 individual sequences of peptaibiotics known as of autumn 2013 (Ayers et al. 2012; Carroux et al. 2013; Figueroa et al. 2013; Kimonyo and Brückner 2013; Röhrich et al. 2012; Röhrich et al. 2013a, b; Chen et al. 2013; Panizel et al. 2013; Ren et al. 2013; Stoppacher et al. 2013), about 950 have been obtained from Trichoderma/Hypocrea species, thus confirming the genus as the most prolific source of this group of non-ribosomal peptide antibiotics (Brückner et al. 1991; Degenkolb and Brückner 2008; Brückner et al. 2009).

Both the taxonomic and metabolic diversity of Trichoderma/ Hypocrea are hypothesised to originate from mycoparasitism or hyperparasitism, which may represent the ancestral life style of this genus (Kubicek et al. 2011). The unique bioactivities of peptaibiotics, resulting from their amphipathicity and helicity, make them ideal candidates to support the parasitic life style of their fungal producers:

Under in vitro-conditions, the parallel formation of peptaibiotics such as the 19-residue trichorzianins ${ }^{2}$ and of hydrolytic enzymes, above all chitinases and $\beta$-1,3-glucanases (Schirmböck et al. 1994), could be demonstrated. This observation led to a widely accepted model describing the synergistic interaction of peptaibiotics and hydrolases in the course of mycoparasitism of Trichoderma atroviride towards Botrytis

\footnotetext{
${ }^{2}$ The trichorzianin-producing strain ATCC 36042 (= CBS 391.92) has originally been identified as T. harzianum (el Hajji et al. 1987) but later shown to belong to T. atroviride (Kuhls et al. 1996).
} 
Table 1 Recently described, non-peptaibiotic secondary metabolites from Trichoderma/Hypocrea species not yet listed in AntiBase 2013

\begin{tabular}{llll}
\hline Producing species and strains & Name of new metabolite(s) & Chemical subclass of metabolites & References \\
\hline T. atroviride G20-12 & $\begin{array}{l}\text { 4'-(4,5-dimethyl-1,3-dioxolan-2-yl)methylphenol } \\
\text { (3'-hydroxybutan-2'-yl)5-oxopyrrolidine-2-carboxylate } \\
\text { Atroviridetide } \\
\text { one bicyclic, three tetracyclic diterpenes }\end{array}$ & Lu et al. 2012 \\
T. atroviride UB-LMA ${ }^{\text {a }}$ & Trichalasin C, D & Di- and tetraterpenes & Cytochalasans \\
T. gamsii SQP 79-1 & Cytosporone S & Spiro-cytochalasan & Adelin et al. 2014 \\
T. sp. FKI-6626 & Trichodermaerin & Diterpenoid lactone & Ding et al. 2012 \\
T. erinaceum AF007 & Ding et al. 2014 & Ishii et al. 2013 \\
\hline
\end{tabular}

${ }^{\mathrm{a}}$ The scientific name of the producer has been misspelled as Trichoderma atroviridae in Adelin et al. (2014)

cinerea (Lorito et al. 1996). Despite this, reports on in vivodetection of peptaibiotics have scarcely been published in the past. Examples include the isolation of hypelcins A and B obtained from ca. $2 \mathrm{~kg}$ of dried, crushed stromata of the mycoparasite Hypocrea peltata (Fujita et al. 1984; Matsuura et al. 1993, 1994) ${ }^{3}$ as well as the detection of antiamoebins in herbivore dung, which have been produced by the coprophilous Stilbella fimetaria (syn. S. erythrocephala) (Lehr et al. 2006).

In order to close this gap, we initiated a screening project aimed at resolving the question as to whether peptaibiotic production in vivo is a common adaptation strategy of Trichoderma/Hypocrea species for colonising and defending ecological niches:

Several Hypocrea specimens were freshly collected in the natural habitat and analysed for the presence of peptaibiotics. Sequences of peptaibiotics found were independently confirmed by analysing the peptaibiome ${ }^{4}$ of pure agar cultures obtained by single-ascospore isolation from the specimens. Using liquid chromatography coupled to electrospray high resolution mass spectrometry we succeeded in detecting 28 peptaibiotics from the polyporicolous Hypocrea pulvinata (Röhrich et al. 2012). Another 49 peptaibiotics were sequenced in Hypocrea phellinicola, a parasite of Phellinus sp., especially Ph. ferruginosus (Röhrich et al. 2013a).

Due to these encouraging results, our screening programme was extended to another nine specimens belonging to seven hitherto uninvestigated mycoparasitic or saprotrophic Trichoderma/Hypocrea species, respectively (Table 2).

\section{Materials and methods}

Specimens of Hypocrea teleomorphs were collected from four different locations in Austria (Table 3). Pure agar cultures

\footnotetext{
${ }^{3}$ Neither a specimen, nor a culture of the hypelcin producer has been deposited. However, misidentification of $H$. peltata is impossible due to its cushion-like big stromata and distinctive bicellular ascospores (Samuels and Ismaiel 2011).

${ }^{4}$ Defined as the dynamic entirety of peptaibiotics formed by a producing fungus under defined culture conditions (Krause et al. 2006a).
}

were obtained by single-ascospore isolations from the respective, freshly collected specimens as previously described by Jaklitsch (2009):

Parts of stromata were crushed in sterile distilled water. The resulting suspension was transferred to cornmeal agar plates (Sigma, St. Louis, Missouri) supplemented with $2 \%(\mathrm{w} / \mathrm{v})$ $\mathrm{D}(+)$-glucose-monohydrate (CMD), and $1 \%(\mathrm{v} / \mathrm{v})$ of an aqueous solution of $0.2 \%(\mathrm{w} / \mathrm{v})$ streptomycin sulfate (Sigma) and $0.2 \%(\mathrm{w} / \mathrm{v})$ neomycin sulfate (Sigma). Plates were incubated overnight at $25^{\circ} \mathrm{C}$. In order to exclude possible contamination by spores of other fungal species, few germinated ascospores from within an ascus were transferred to fresh plates of CMD using a thin platinum wire. The plates were sealed with Parafilm (Pechiney, Chicago, Illinois) and incubated at $25{ }^{\circ} \mathrm{C}$. As all species listed in Table 2 could unambiguously be identified by their morphological and growth characteristics (Jaklitsch 2009, 2011), no molecular phylogenetic analyses needed to be performed.

Detailed descriptions of chemicals, extraction and work-up procedures for specimens and agar plate cultures, cultivation methods, as well as comprehensive protocols for HPLC/QTOFESI-HRMS were given by Röhrich et al. (2012, 2013a). For routine screening, a high-resolution micrOTOF Q-II mass spectrometer with orthogonal ESI source (Bruker Daltonic, Bremen, Germany), coupled to an UltiMate 3000 HPLC (Dionex, Idstein, Germany), was used. Samples, which have been screened negative with the above HPLC/MS system, were re-examined using a maXis $3 \mathrm{G}$ QTOF mass spectrometer with orthogonal ESI source (Bruker Daltonic, Bremen, Germany), coupled to an UltiMate 3000 UHPLC (Dionex, Idstein, Germany) as previously described (Röhrich et al. 2012, 2013a).

\section{Results and discussion}

General considerations. All strains investigated in this study represent phylogenetically well-defined species (Tables 2 and 3). This is in contrast to most of the reports published until the end of the 1990s, when peptaibiotic production by the genus Trichoderma/Hypocrea was - according to Rifai's classification 
Table 2 Habitat and geographic distribution of Hypocrea species included in this study

\begin{tabular}{|c|c|c|c|}
\hline Species & Clade & Habitat & Geographic distribution \\
\hline $\begin{array}{l}\text { Hypocrea thelephoricola } \\
\quad \text { (Trichoderma thelephoricola) }\end{array}$ & Chlorospora & $\begin{array}{l}\text { On and around basidiomata of Steccherinum } \\
\text { ochraceum, on wood and bark }\end{array}$ & North America (USA), Europe (Austria) \\
\hline $\begin{array}{l}\text { Hypocrea minutispora } \\
\quad \text { (Trichoderma minutisporum) }\end{array}$ & $\begin{array}{l}\text { Pachybasium } \\
\text { (core group) }\end{array}$ & $\begin{array}{l}\text { Most common hyaline-spored species in } \\
\text { temperate zones }\end{array}$ & $\begin{array}{l}\text { Europe (Austria, Czech Republic, } \\
\text { Denmark, Estonia, France, Germany, } \\
\text { Spain, Sweden, United Kingdom) and } \\
\text { North America (USA) }\end{array}$ \\
\hline $\begin{array}{l}\text { Hypocrea sulphurea } \\
\text { (Trichoderma } \mathrm{sp.)}\end{array}$ & Hypocreanum & On basidiomes of Exidia spp. & $\begin{array}{l}\text { Europe (Eastern Austria, Ukraine), } \\
\text { North America (USA), Japan }\end{array}$ \\
\hline $\begin{array}{l}\text { Hypocrea citrina } \\
\quad \text { (Trichoderma lacteum) }\end{array}$ & Hypocreanum & $\begin{array}{l}\text { Spreading from stumps or tree bases on soil } \\
\text { and debris such as small twigs, bark, leaves, } \\
\text { dead plants; incorporating also living plants; } \\
\text { more rarely on bark of logs on the ground. } \\
\text { Most typically in mixed coniferous forest }\end{array}$ & $\begin{array}{l}\text { widespread and locally common, mostly } \\
\text { found from the end of August to the } \\
\text { beginning of October. Europe (Austria, } \\
\text { Belgium, Czech Republic, Netherlands, } \\
\text { Sweden, United Kingdom) and North } \\
\text { America (USA) }\end{array}$ \\
\hline $\begin{array}{l}\text { Hypocrea voglmayrii } \\
\text { (Trichoderma voglmayrii) }\end{array}$ & Lone lineage & $\begin{array}{l}\text { On dead, mostly corticated branches and } \\
\text { small trunks of Alnus alnobetula }(=A \text {. viridis) } \\
\text { and } A \text {. incana standing or lying on the } \\
\text { ground }\end{array}$ & $\begin{array}{l}\text { Austria (at elevations of } 1,000-1,400 \mathrm{~m} \\
\text { in the upper montane vegetation zone } \\
\text { of the Central Alps) }\end{array}$ \\
\hline $\begin{array}{l}\text { Hypocrea gelatinosa } \\
\text { (Trichoderma gelatinosum) }\end{array}$ & Lone lineage & $\begin{array}{l}\text { On medium- to well-decayed wood, also on } \\
\text { bark and overgrowing various fungi }\end{array}$ & $\begin{array}{l}\text { Europe (Austria, France, Germany, } \\
\text { Netherlands, Slovenia, Ukraine, } \\
\text { United Kingdom) }\end{array}$ \\
\hline $\begin{array}{l}\text { Hypocrea parmastoi } \\
\quad \text { (Trichoderma } \mathrm{sp} . \\
\quad \text { [sect. Hypocreanum]) }\end{array}$ & Lone lineage & $\begin{array}{l}\text { On medium- to well-decayed wood and bark } \\
\text { of deciduous trees }\end{array}$ & $\begin{array}{l}\text { Europe (Austria, Estonia, Finland, } \\
\text { France, Germany); uncommon }\end{array}$ \\
\hline
\end{tabular}

Data were compiled from Chaverri and Samuels (2003), Overton et al. (2006a, b), and Jaklitsch (2009, 2011)

(1969) - mostly attributed to one of the four common species T. viride, T. koningii, T. harzianum, T. longibrachiatum, and sometimes to T. pseudokoningii and T. aureoviride. Careful inspection of the literature published prior to the turn of the millennium revealed that only three of the Trichoderma strains, reported as sources of 'classical' peptaibiotics have correctly been identified and appropriately been deposited, viz. the paracelsin-producing T. reesei QM 9414 (Brückner and Graf

Table 3 Habitat and geographic origin of Hypocrea isolates included in this study

\begin{tabular}{|c|c|c|c|}
\hline Isolate & Substrate & Collecting information & Culture \\
\hline H. thelephoricola & Steccherinum ochraceum/Carpinus betulus & & CBS 133226 \\
\hline H. gelatinosa & Carpinus betulus & & CBS 133223 \\
\hline H. minutispora & Carpinus betulus & $\begin{array}{l}\text { Austria, Niederösterreich, Wien- } \\
\text { Umgebung, Mauerbach, MTB }\end{array}$ & CBS 133224 \\
\hline H. sulphurea 1 & Exidia glandulosa/Carpinus betulus & 7763/1, 13 June 2011,W. Jaklitsch & $\begin{array}{l}\text { not } \\
\text { deposited }^{\mathrm{a}}\end{array}$ \\
\hline H. sulphurea $2^{\mathrm{b}}$ & Exidia glandulosa/Carpinus betulus & & CBS 133227 \\
\hline H. sulphurea 3 & Exidia sp. & $\begin{array}{l}\text { Austria, Vienna, Lainzer Tiergarten, } \\
\text { near Nikolaitor, } 25 \text { September } 2011 \text {, } \\
\text { H. Voglmayr }\end{array}$ & not deposited \\
\hline H. parmastoi & Fagus sylvatica & $\begin{array}{l}\text { Austria, Niederösterreich, Wien- } \\
\text { Umgebung, Mauerbach, MTB } \\
\text { 7763/1, } 30 \text { October 2011, } \\
\text { W. Jaklitsch (Hypo 656) }\end{array}$ & CBS 133242 \\
\hline H. voglmayrii & Alnus alnobetula & $\begin{array}{l}\text { Austria, Styria, Schladming, Untertal, } \\
\text { at Riesachfälle, } 12 \text { June } 2011, \mathrm{H} \text {. } \\
\text { Voglmayr }\end{array}$ & CBS 133225 \\
\hline H. citrina & Pinus sylvestris litter, ground & $\begin{array}{l}\text { Austria, Carinthia, Obermieger, } \\
\text { Sabuatach, MTB } 9452 / 2,23 \\
\text { September 2011, W. Jaklitsch } \\
\text { (Hypo 654) }\end{array}$ & CBS 133244 \\
\hline
\end{tabular}

${ }^{\text {a }}$ Stroma immature, isolation of single germinable ascospores impossible

${ }^{\mathrm{b}}$ The specimens of $H$. sulphurea 1 and 2 were collected from two different trees found in the same area 
1983; Brückner et al. 1984), the trichosporin/trichopolyn producer T. polysporum TMI 60146 (Iida et al. 1990, 1993, 1999), and the paracelsin E-producing T. saturnisporum CBS 330.70 (Ritieni et al. 1995). Furthermore, none of the numerous peptaibiotic-producing strains, reported to belong to those six Trichoderma species mentioned above, has subsequently been verified by phylogenetic analyses. Statements on the identity of the producers must therefore be regarded with great caution, unless it is being described how isolates were identified (Degenkolb et al. 2008). Unfortunately, most of the peptaibiotic-producing Trichoderma/Hypocrea strains investigated prior to 2000 have never been appropriately deposited either $i$ ) in a publicly accessible culture collection or $i i$ ) in an International Depositary Authority (IDA) under the
Fig. 1 Base-peak

chromatograms (BPCs) analysed with the micrOTOF-Q II.

a specimen of $H$. thelephoricola, b plate culture of $H$. thelephoricola on PDA. $\dagger$, non-peptaibiotic metabolite(s); $\sharp$, co-eluting peptaibiotics, not sequenced. The $y$-axis of all BPC chromatograms in this publication refers to relative ion intensities a

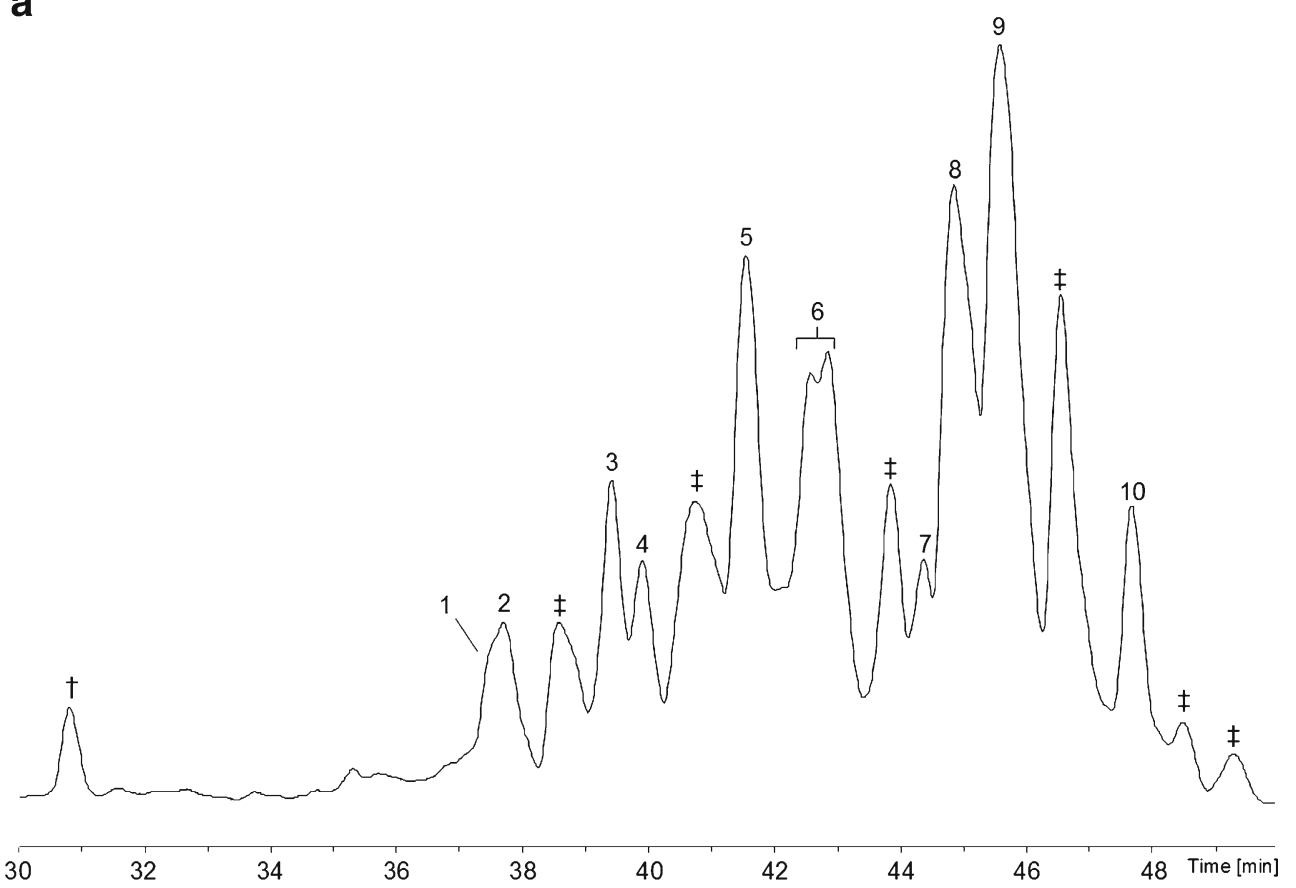

b

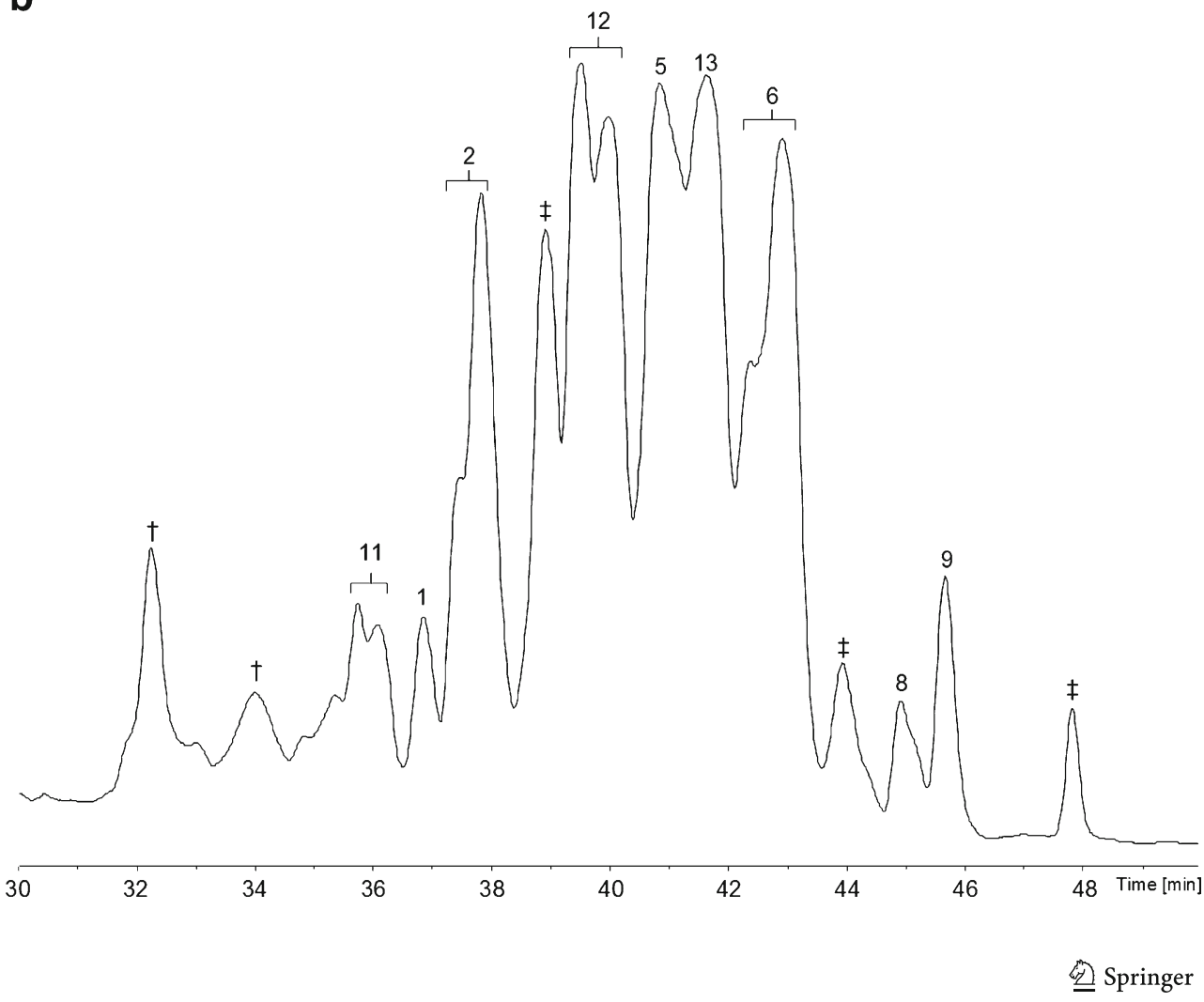




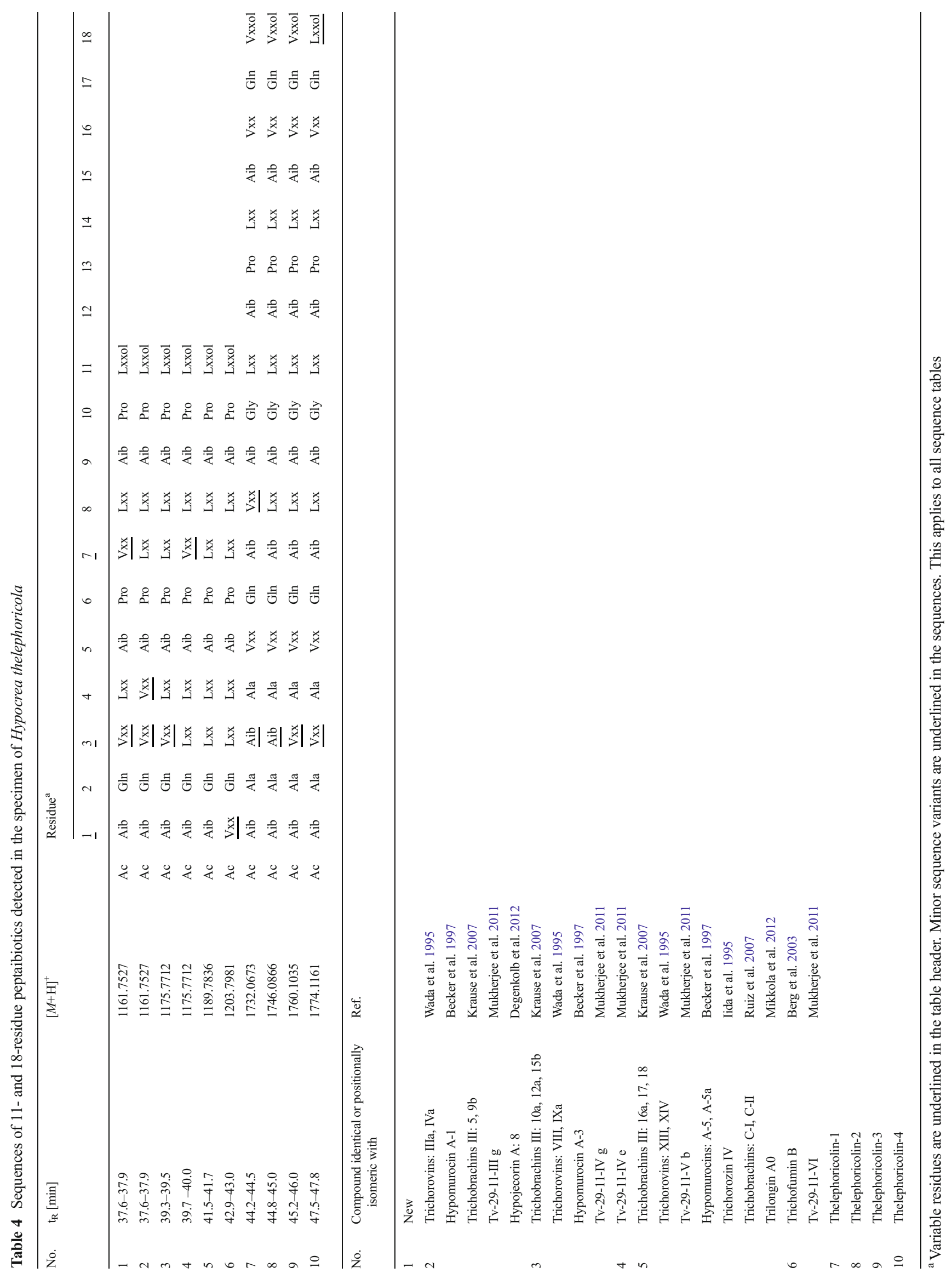




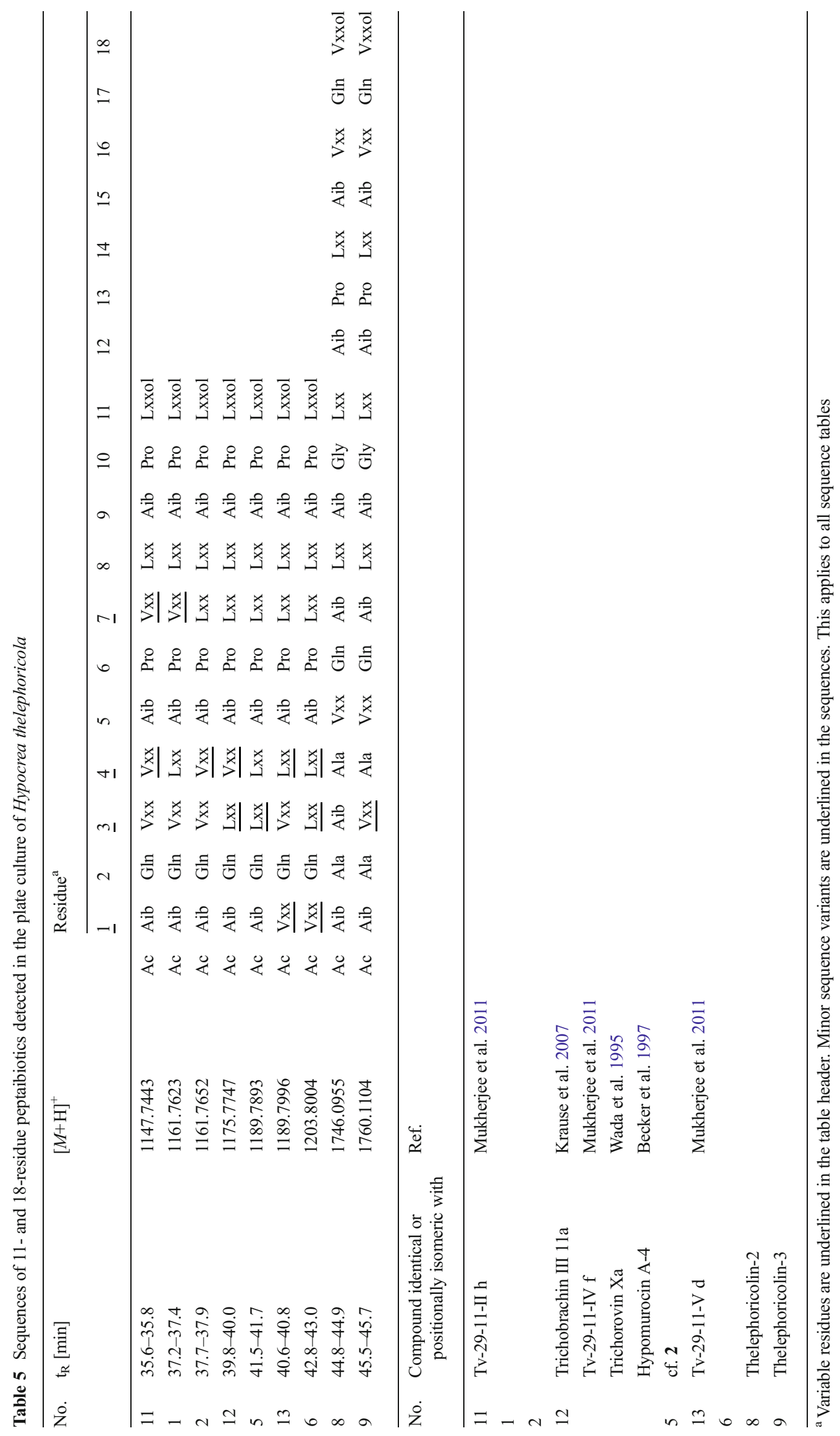




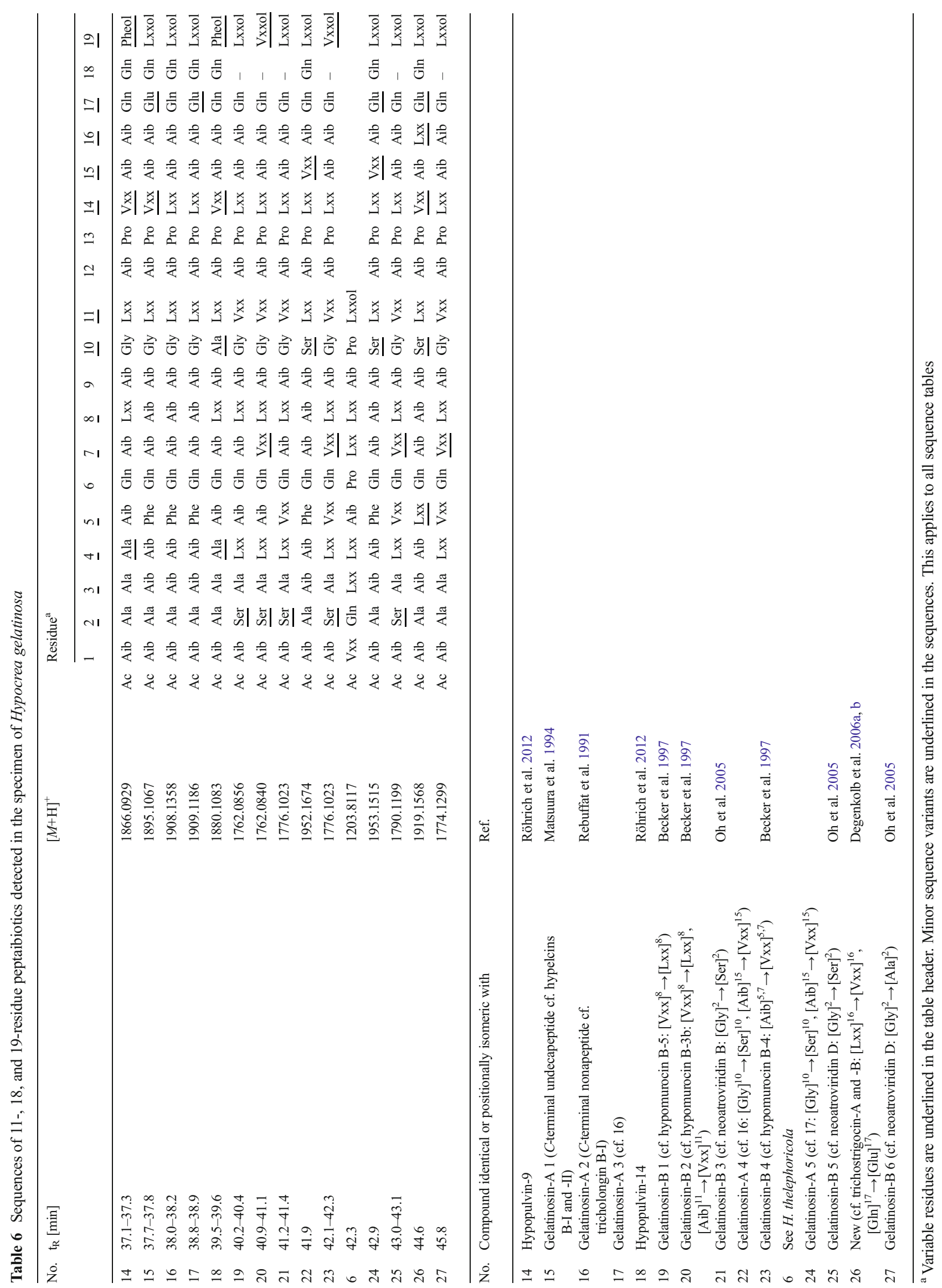




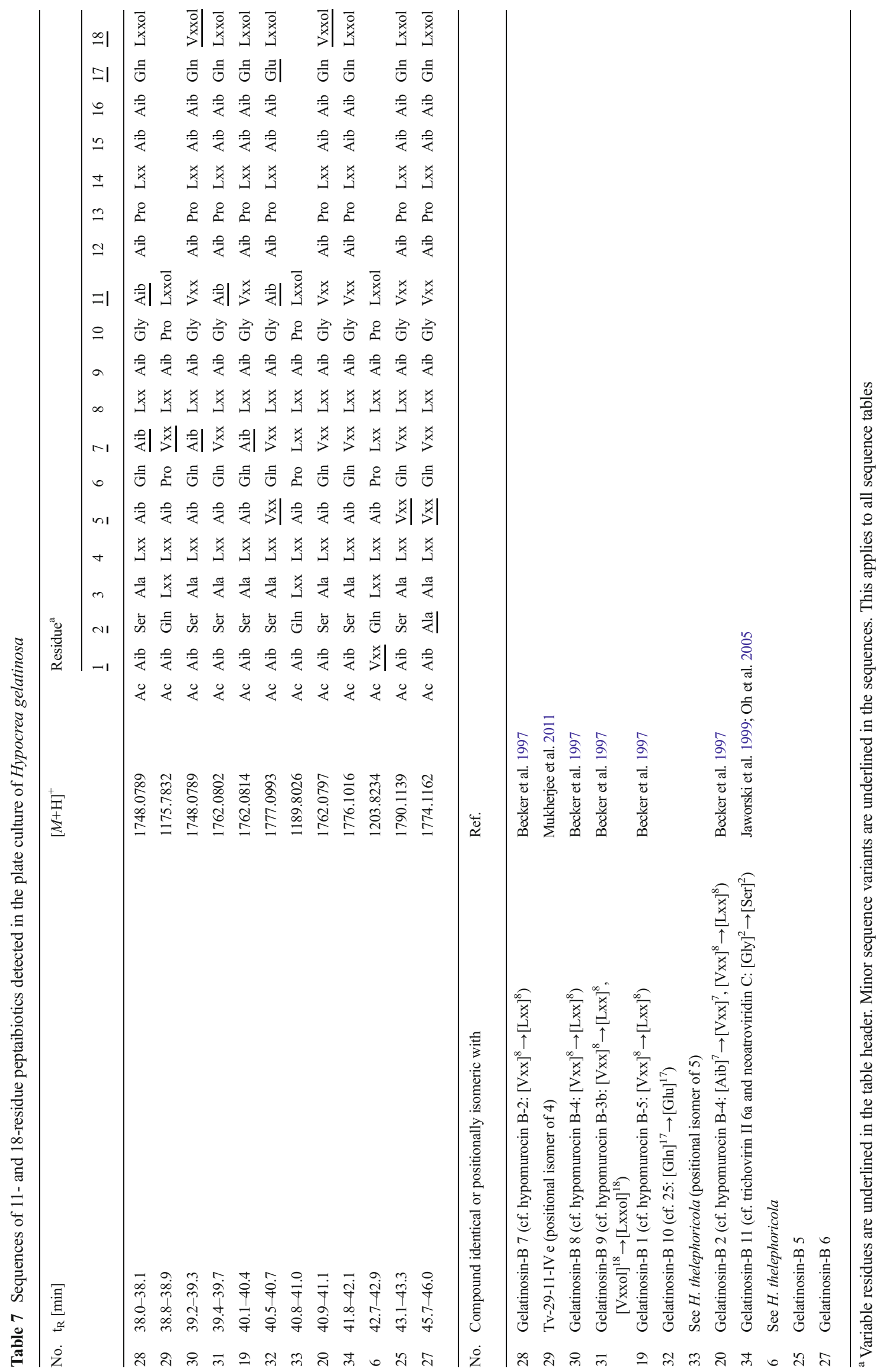


conditions of the Budapest Treaty; thus, they are not available to independent academic research. As misidentifications persist to be a continuous problem, not only in the older literature (Neuhof et al. 2007), the authors prefer to introduce new names for the peptaibiotics sequenced in this study. Those new names refer to the epithets of the producing species.
Screening of Hypocrea thelephoricola. Ten peptaibols from the specimen of $H$. thelephoricola were sequenced (Fig. 1a). Six of them, compounds 1-6, are 11-residue sequences displaying the classical building scheme of subfamily 4 (SF4) peptaibols (Chugh and Wallace 2001; Degenkolb et al. 2012; Röhrich et al. 2013b). Compound $\mathbf{1}$ is new,
Fig. 2 Base-peak chromatograms (BPCs) analysed with the micrOTOF-Q II.

a specimen of $H$. gelatinosa, b plate culture of $H$. gelatinosa on PDA. $\dagger$, non-peptaibiotic metabolites, not sequenced; $\$$, co-eluting peptaibiotics, not sequenced a

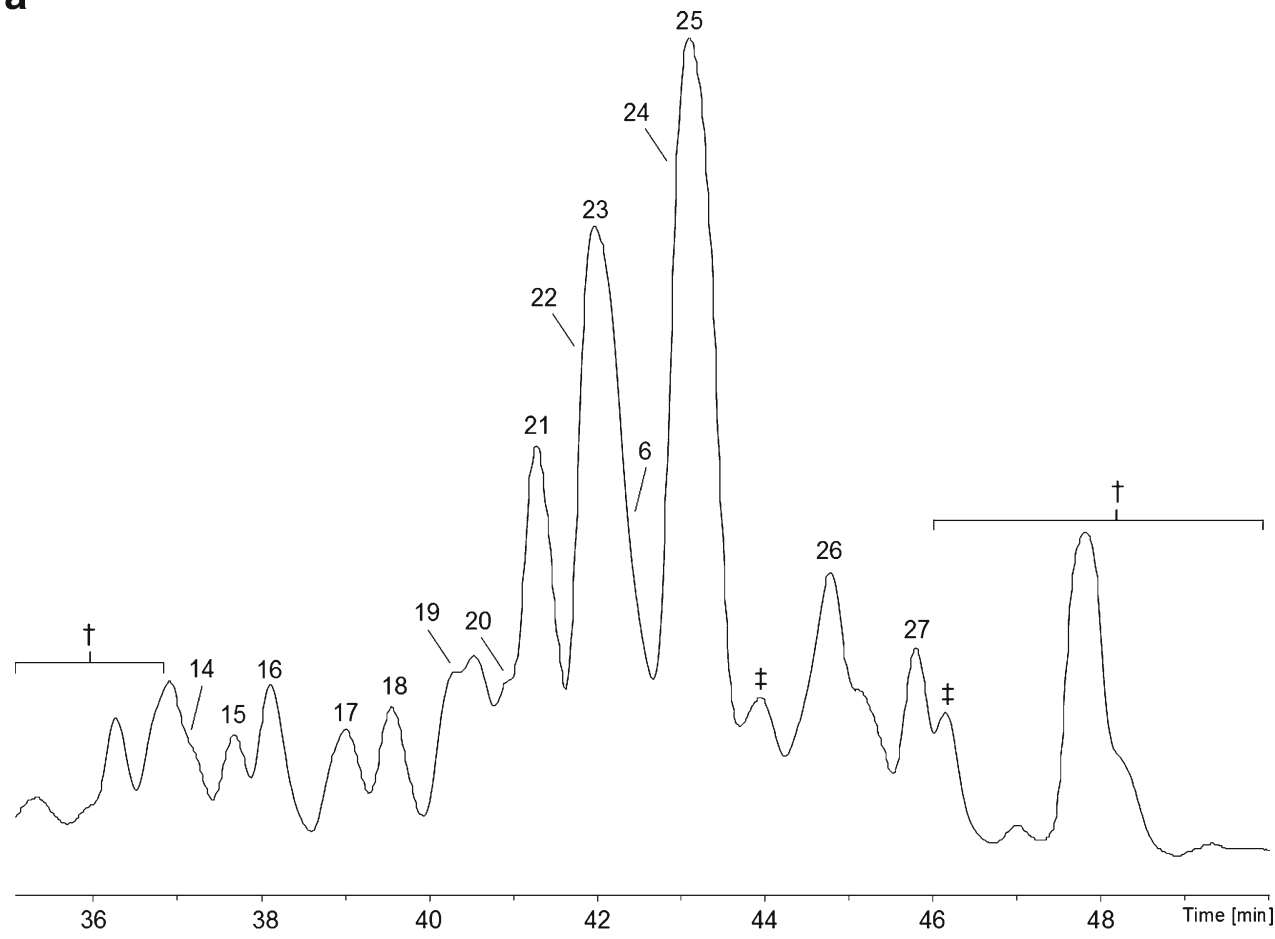

b

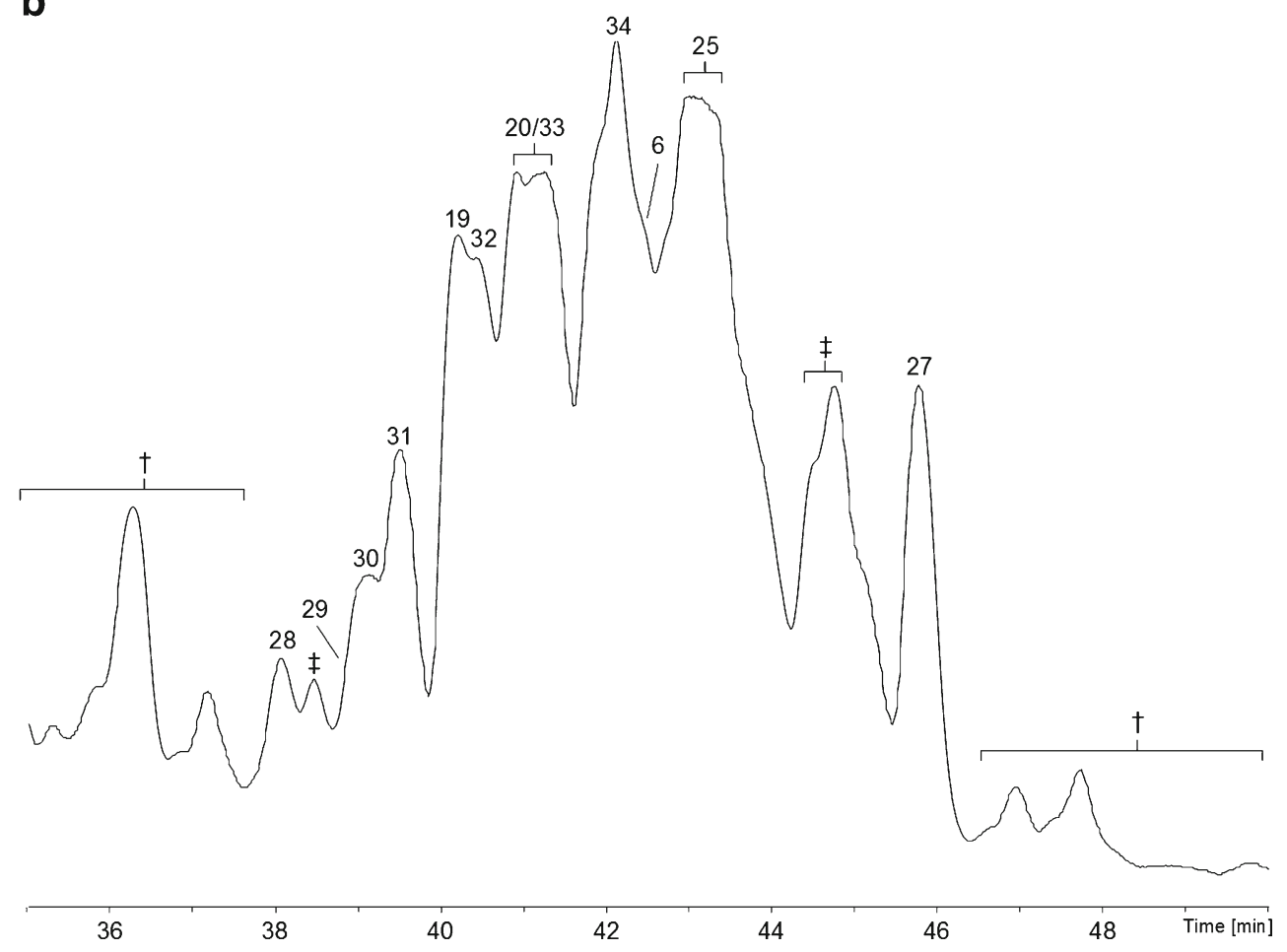


Fig. 3 Base-peak chromatograms (BPCs) analysed with the micrOTOF-Q II.

a specimen of $H$. voglmayrii; b plate culture of $H$. voglmayrii on PDA. $\dagger$, non-peptaibiotic metabolite(s); peptaibiotics,

not sequenced; $\mathrm{H}$, minor peptabiotics containing $O$-prenylated tyrosinol ( $\left.\operatorname{Tyr}\left(\mathrm{C}_{5} \mathrm{H}_{8}\right) \mathrm{ol}\right)$, the $C$-terminus of which could not be sequenced a

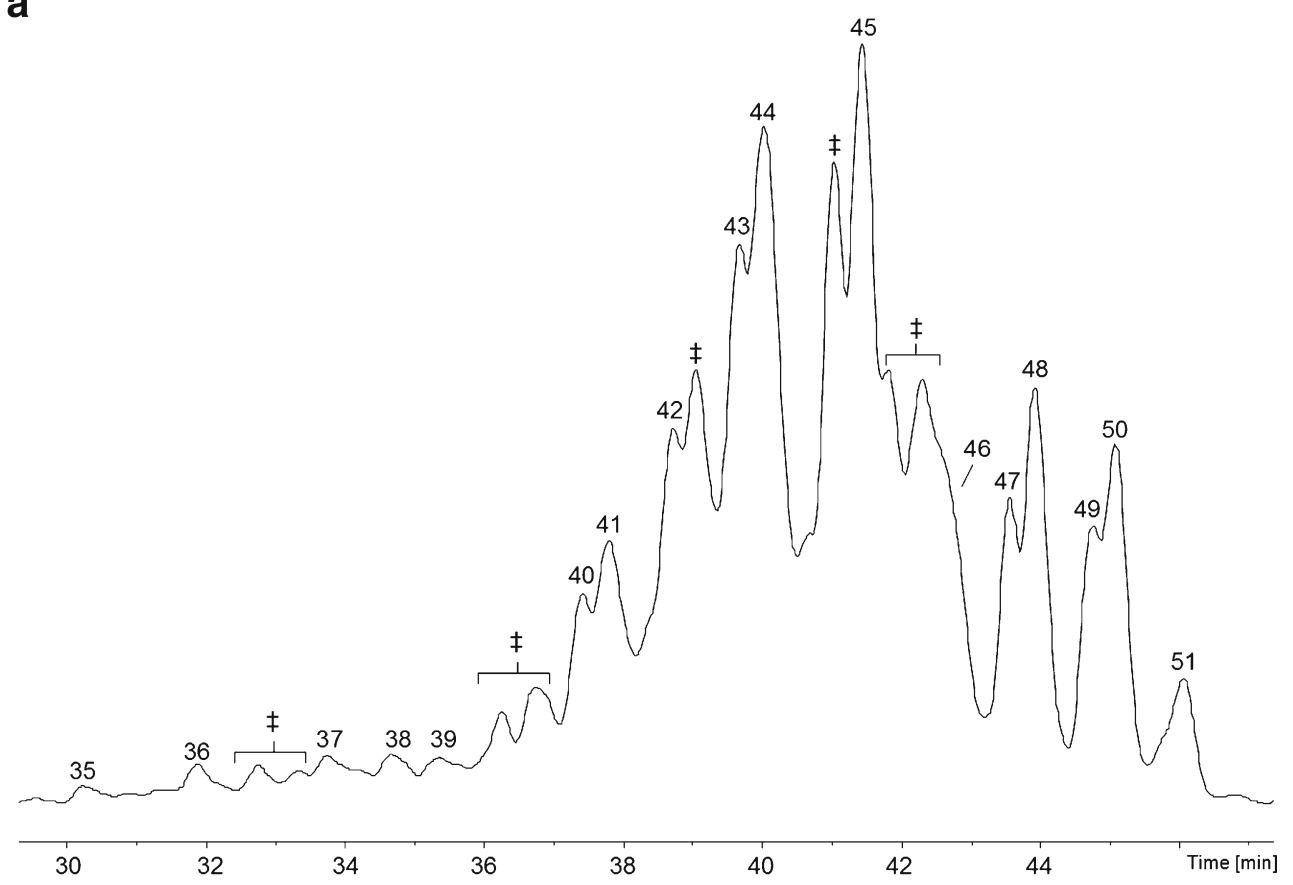

b

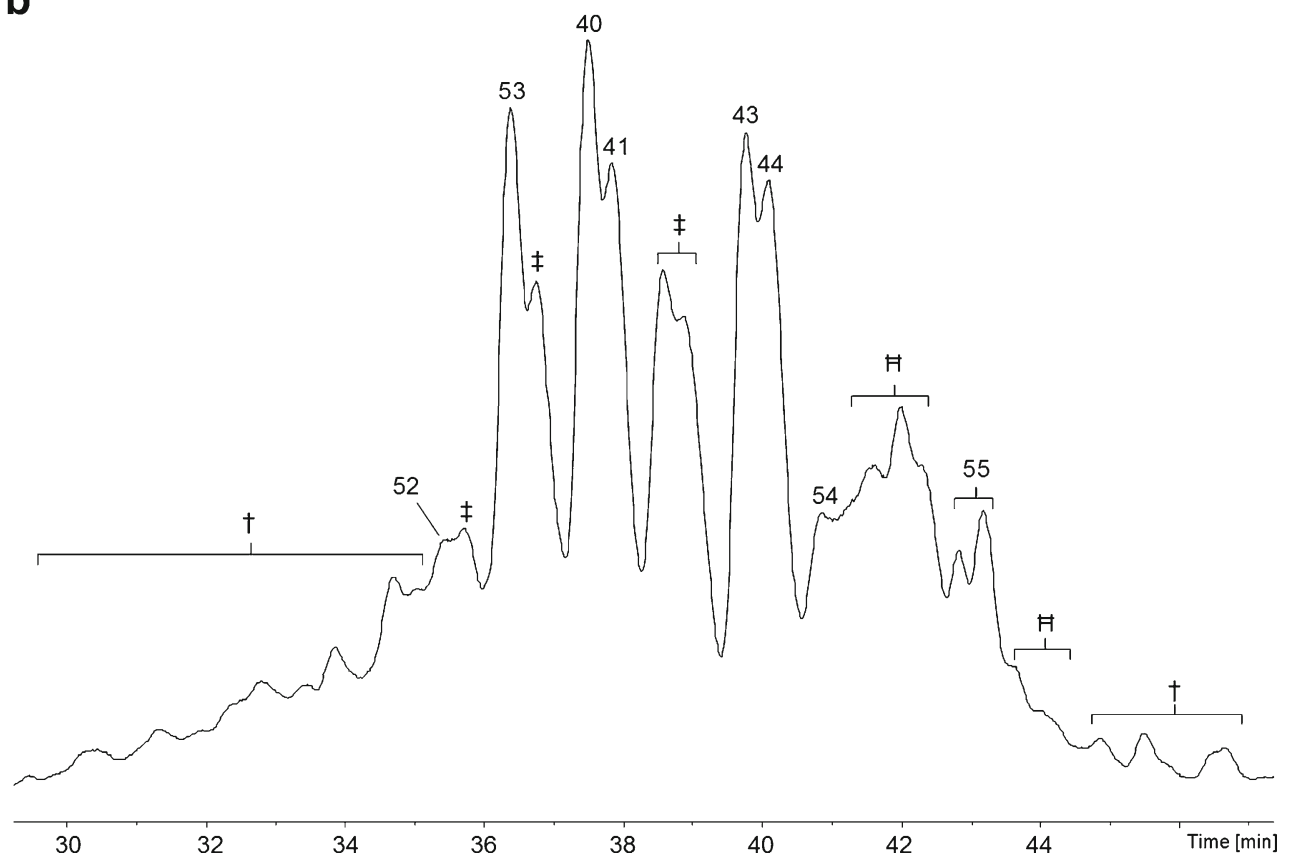

whereas compounds 2-6 are likely to represent 11-residue peptaibols, which have been described before (Tables 4 and 5, Table S1a and S1b). Compounds 7-10 are new 18residue peptaibols, named thelephoricolins $\mathbf{1}-\mathbf{4}$ sharing some

\footnotetext{
${ }^{5}$ The trichotoxin A-producing strain NRRL 5242 (now A-18169 in the ARS culture collection $=$ CBS $361.97=$ ATCC 38501 ) has originally been identified as $T$. viride but was subsequently reidentified as T. asperellum (Lieckfeldt et al. 1999; Samuels et al. 1999). The trichotoxin B (= trichovirin) producer, strain NRRL 5243 (= ATCC 90200), is not in the ARS catalogue but available as A-18207.
}

structural similarity ( $N$-terminal dipeptide, $[\mathrm{Gln}]^{6} /[\mathrm{Aib}]^{7}, C$ terminal heptapeptide) with trichotoxins $\mathrm{A}-50 \mathrm{H}$ and $\mathrm{A}-50-\mathrm{J}^{5}$ (Brückner and Przybylski 1984). The plate culture produced predominantly 11-residue SF4-peptaibols (compounds $\mathbf{1 , 2}, \mathbf{5}$, 6, 11-13), but only two 18-residue peptaibols, thelephoricolins 2 and $\mathbf{3}$ (Fig. 1b).

Screening of Hypocrea gelatinosa. A single strain (ICMP 5417) of this species has previously been screened positive Aib and Iva by a GC/MS-based approach (Brückner et al. 1991). From the specimen of $H$. gelatinosa, 


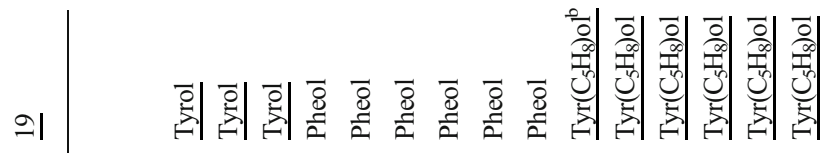

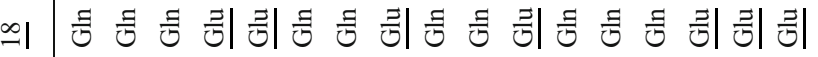

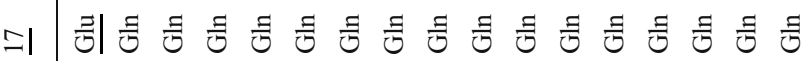

牛

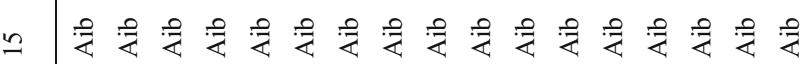

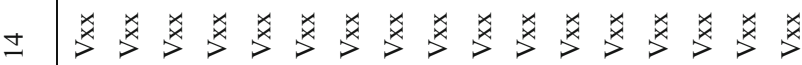

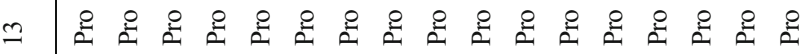

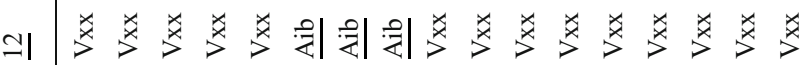

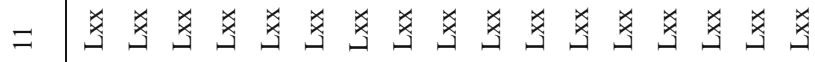

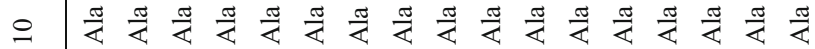

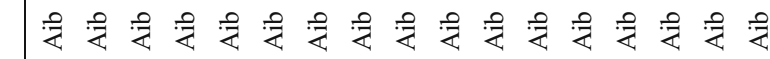

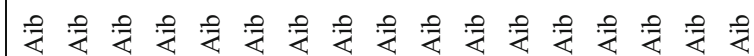

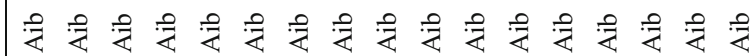

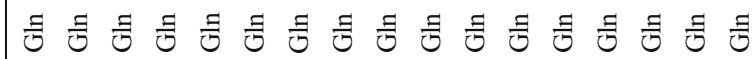

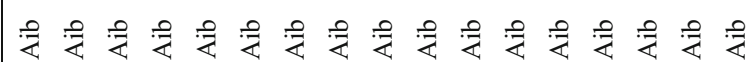

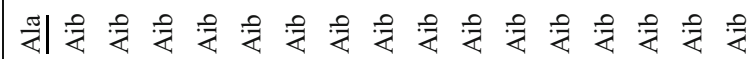

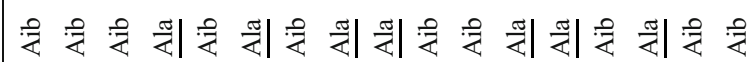

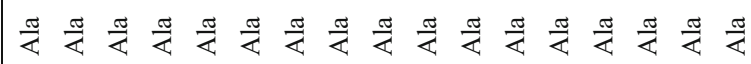

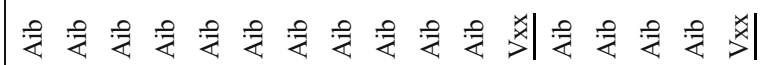

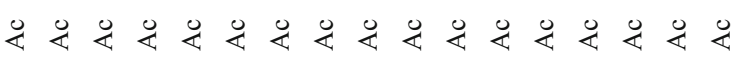

宅

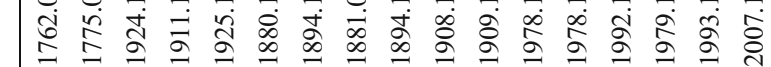

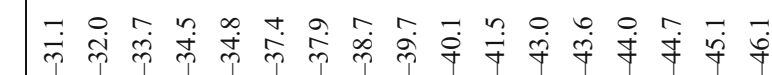

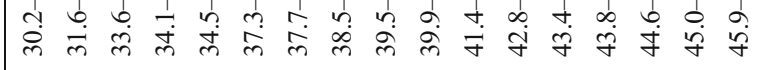

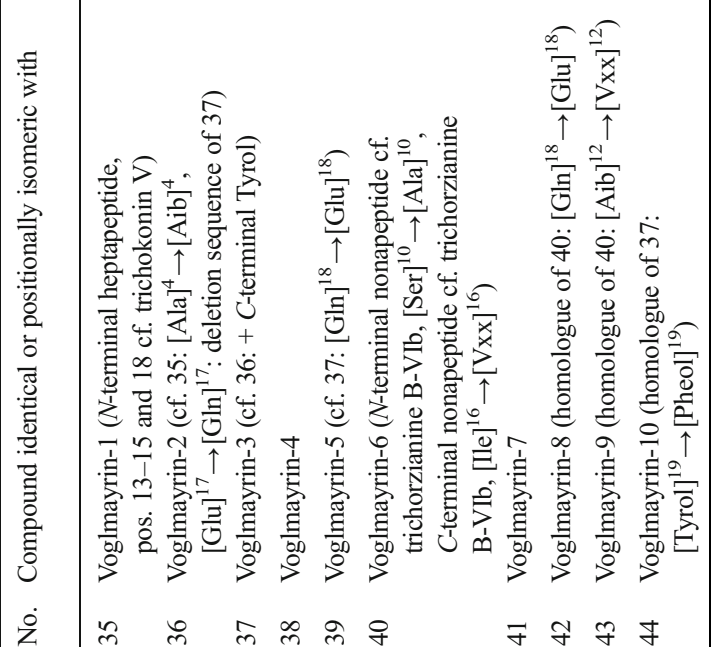


14 compounds 14-27, six 18-residue and eight 19-residue peptaibols, were sequenced. All of them but compounds $\mathbf{1 4}$ and 18 are new (Tables 6 and 7, Table S2a and S2b; Fig. 2a). The 18-residue sequences, compounds 19-21, 23, 25, and 27, named gelatinosins B 1-6, resemble hypomurocins ${ }^{6}$ or neoatroviridins ${ }^{7}$. Two of the 19-residue sequences, compounds 14 and 18, are identical with the recently described hypopulvins from $H$. pulvinata (Röhrich et al. 2012). The new compounds 15-17, 22, and 24, named gelatinosins A 1-5, exhibit a partially new building scheme - the residue in position 5 of the peptide chain was assigned as Phe, based upon HR-MS/MS data. In contrast to this, the new 19-residue compound 26 displays a different building scheme, resembling trichostrigocinsA/B (Degenkolb et al. 2006a). The plate culture of $H$. gelatinosa was shown to produce three minor 11residue SF4-peptaibols, compounds $\mathbf{6 , 2 9}$, and 33, and nine gelatinosins $B$ (compounds, 19, 20, 25, 27, 28, 30-32, and 34), 18-residue peptaibols of the hypomurocin/neoatroviridintype. However, 19-residue peptaibols have not been detected (Tables 6 and 7, Table S2a and S2b; Fig. 2b).

Compound $\mathbf{6}$ is likely to represent the second one of the partial sequences reported by Krause et al. (2006a) for H. gelatinosa CBS 724.87. In contrast, the first one, for which an unknown $N$-terminal residue $\mathrm{m} / \mathrm{z} 157$ was claimed (Krause et al. 2006a), could not be detected in this screening.

Screening of Hypocrea voglmayrii. The most notable species screened is by far H. voglmayrii (Fig. 3), the specimen of which produced two 18-residue deletion sequences, compounds 35 and 36, which lack the $C$-terminal amino alcohol, as well as 15 19-residue peptaibols, compounds 37-51 (Tables 8 and 9, Table S3a and S3b). As all of them are new, the names voglmayrins 1-17 are introduced. They partly resemble the building schemes of trichokonin V (Huang et al. 1995) and of trichorzianins B (Rebuffat et al. 1989). Six of the major compounds (40-45) carry a $C$-terminal phenylalaninol (Pheol) residue, whereas three minor compounds (37-39) terminate in tyrosinol (Tyrol) - a residue that has not been described for peptaibiotics until only recently (Röhrich et al. 2013a). Another six major compounds (46-51) display an additional fragment ion $68.0628 \pm 2.3 \mathrm{mDa}$ at their $C$-terminus (Fig. 4). Thus, the $p$-OH group of their Tyrol residue is hypothesised to be substituted by a prenyl or isoprenyl residue $\left(\mathrm{C}_{5} \mathrm{H}_{8}\right.$, for details see paragraph below). In contrast to this, major 19-residue peptaibols produced by the plate culture, compounds 40, 41, 43, 44, and two additional compounds, 52 and 53, voglmayrins-18 and -19, terminate in Pheol. HR-MS data clearly confirm the presence of additional minor

\footnotetext{
${ }^{6}$ Hypomurocins have been isolated from strain IFO 31288 (Becker et al. 1997), originally misidentified as Hypocrea muroiana. The producer belongs, in fact, to T. atroviride (Samuels et al. 2006).

${ }^{7}$ The neoatroviridin producer T. atroviride F80317 (Oh et al. 2005) has neither been deposited with an IDA, nor has its identity been verified phylogenetically.
} 


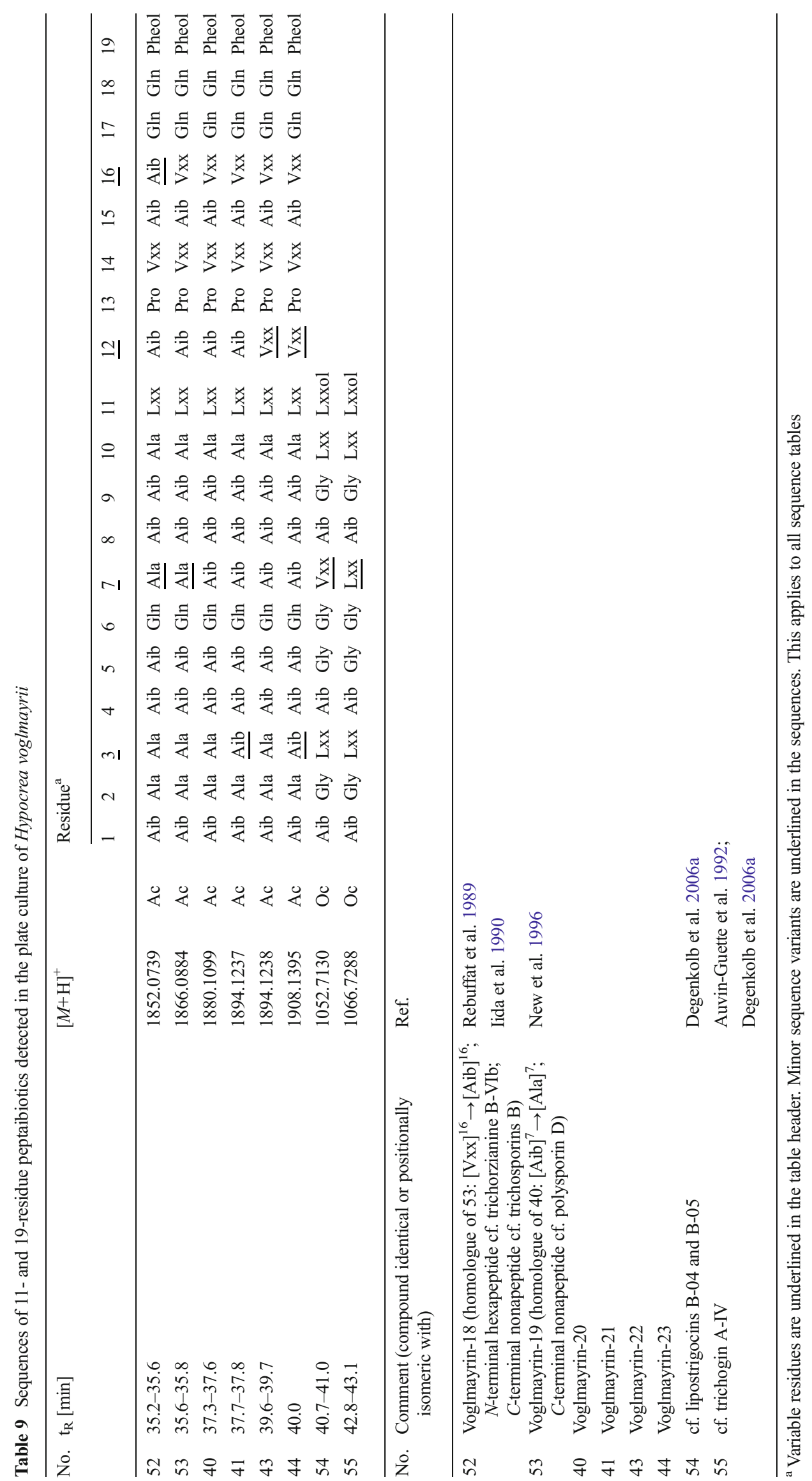




\section{a}

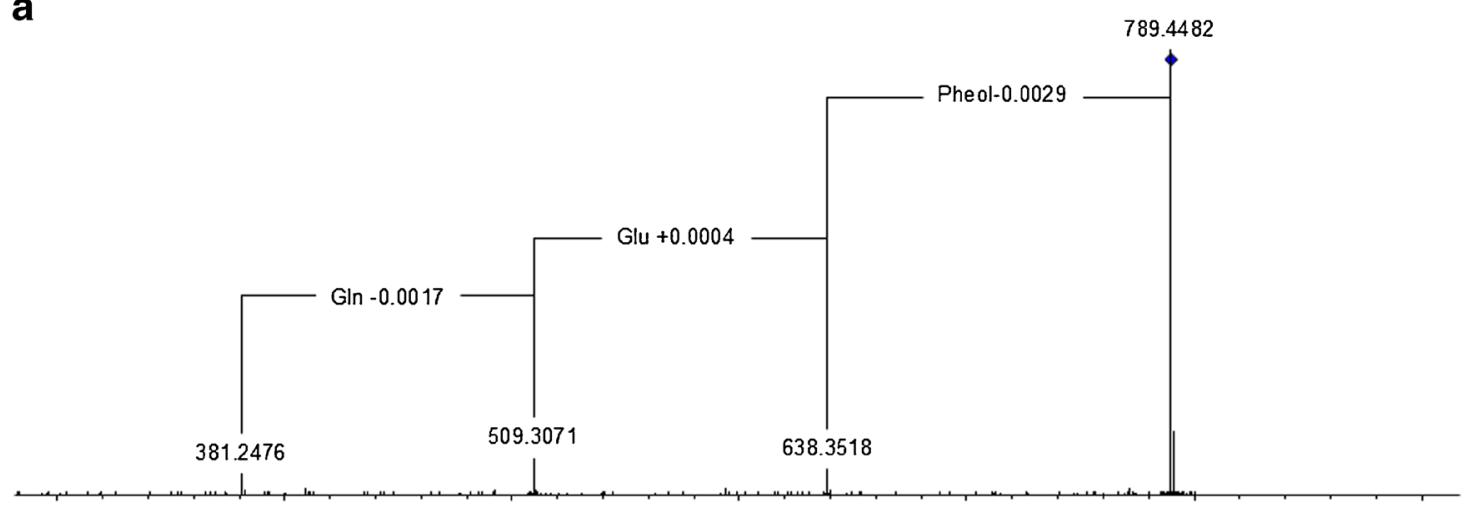

b

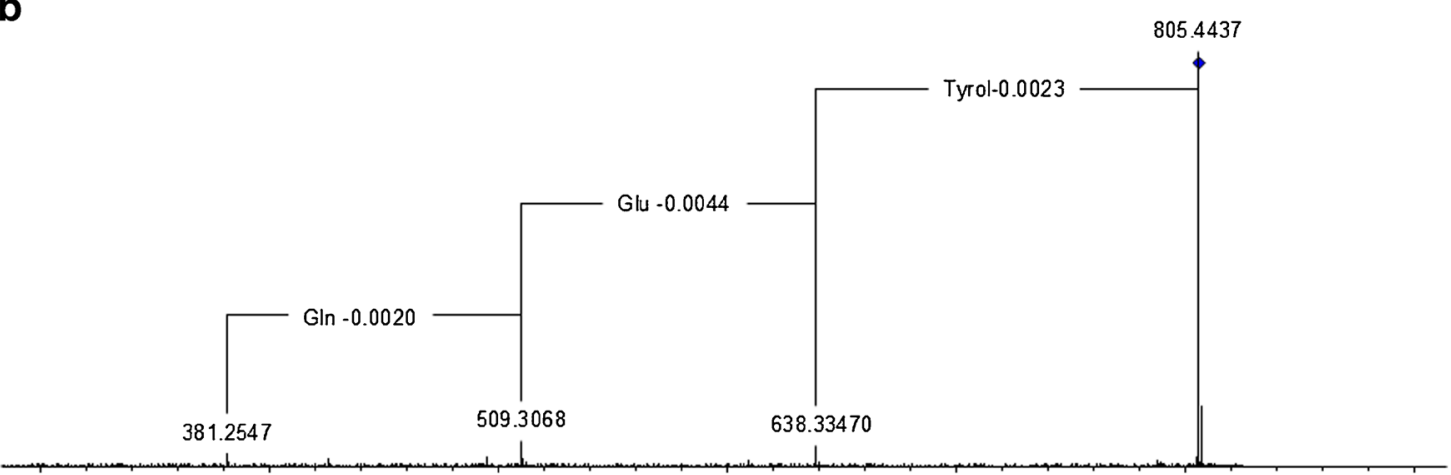

C

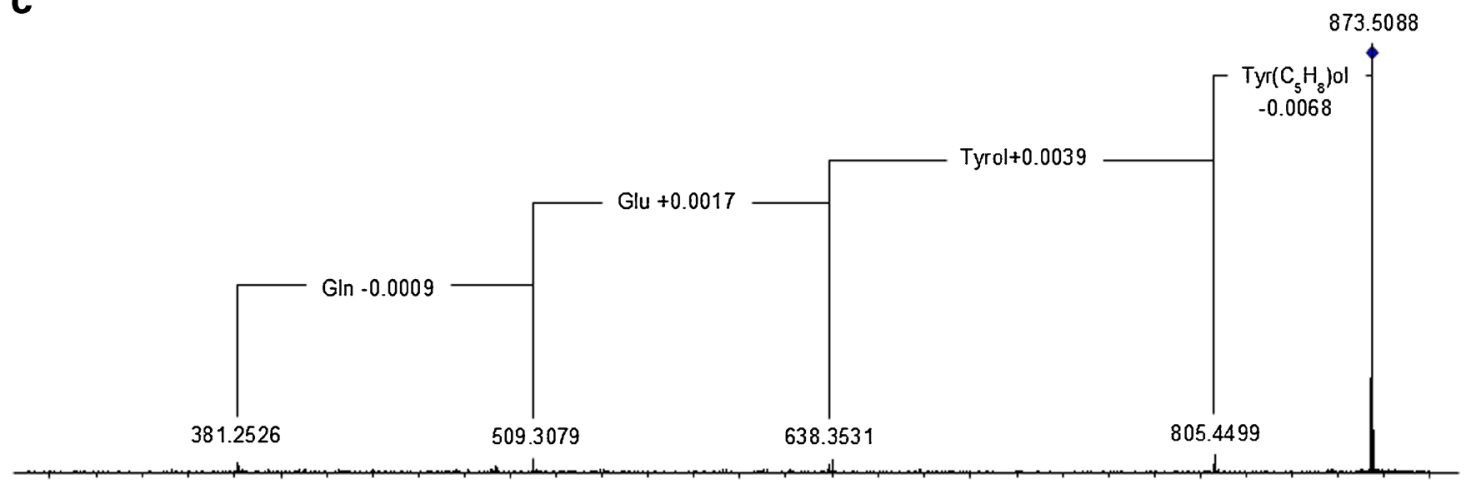

d

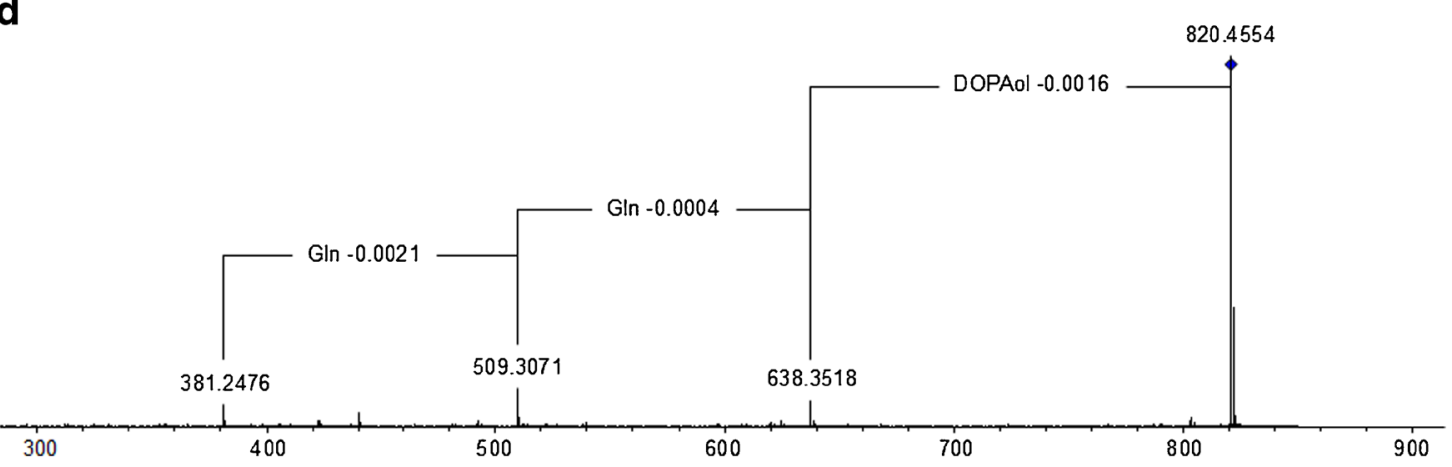

Fig. 4 HR-MS/MS sequencing of diagnostic, $C$-terminal $y$-ions, displaying novel and recurrent residues of $\beta$-amino alcohols. a phenylalaninol (Pheol); b tyrosinol (Tyrol); c $O$-prenylated tyrosinol $\left(\operatorname{Tyr}\left(\mathrm{C}_{5} \mathrm{H}_{8}\right)\right.$ ol); d dihydroxyphenylalaninol (DOPAol) 


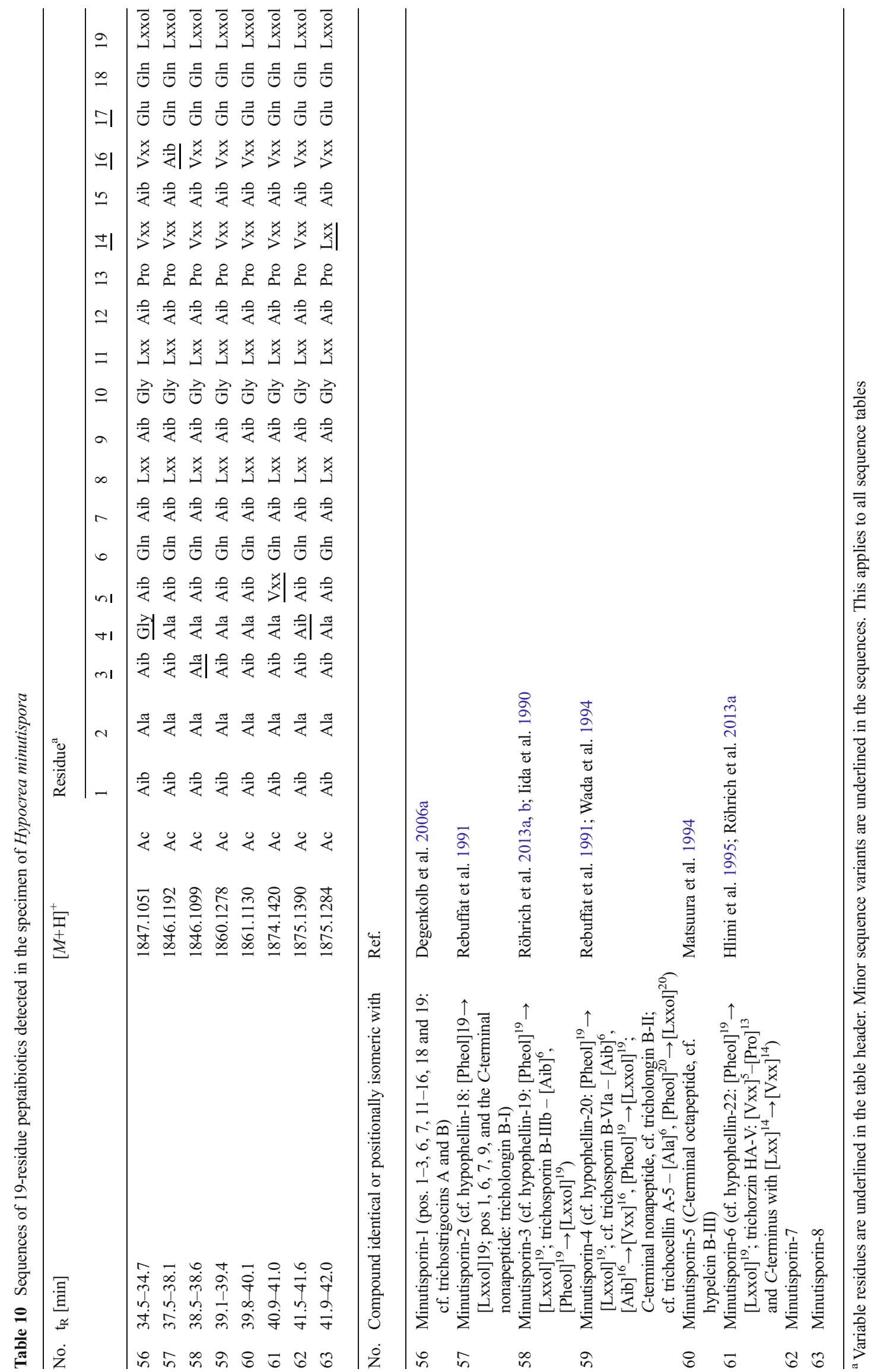




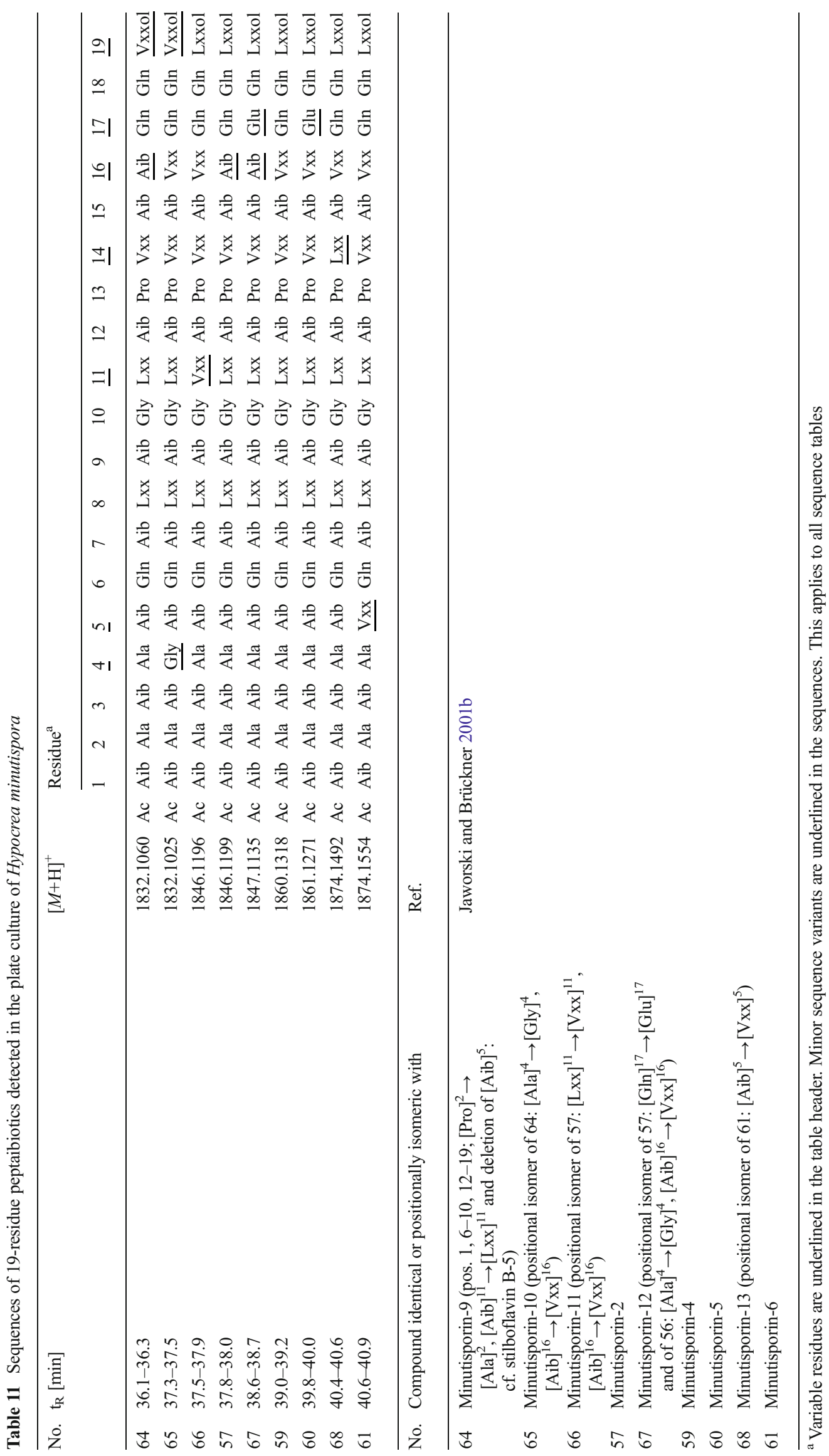


components carrying a $C$-terminal Tyrol or prenylated Tyrol residue, respectively. Unfortunately, the intensities were too low for MS/MS sequencing of the respective $y_{6}$ ions. Two 11-residue lipopeptaibols, compound 54 and 55, resembling lipostrigocin B-04/B-05 (Degenkolb et al. 2006a) and trichogin A IV (Auvin-Guette et al. 1992), have also been sequenced.

Screening of Hypocrea minutispora. The specimen of $H$. minutispora has been shown to produce a mixture of eight new 19-residue peptaibols, compounds 56-63, named
Fig. 5 Base-peak chromatograms (BPCs) analysed with the micrOTOF-Q II.

a specimen of $H$. minutispora,

b plate culture of $H$. minutispora

on PDA. $\uparrow$, non-peptaibiotic metabolite(s); \$, co-eluting peptaibiotics, not sequenced a

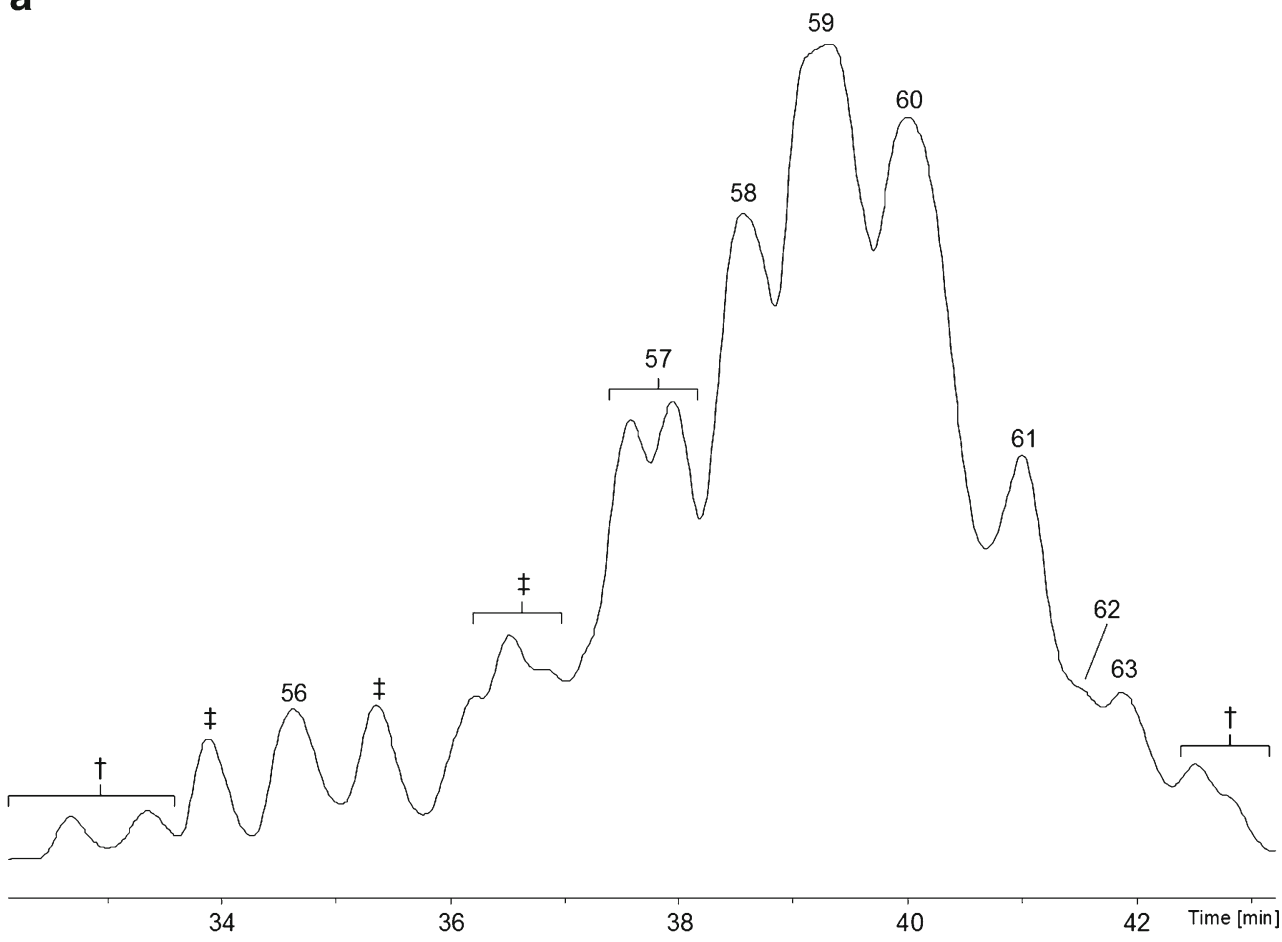

b

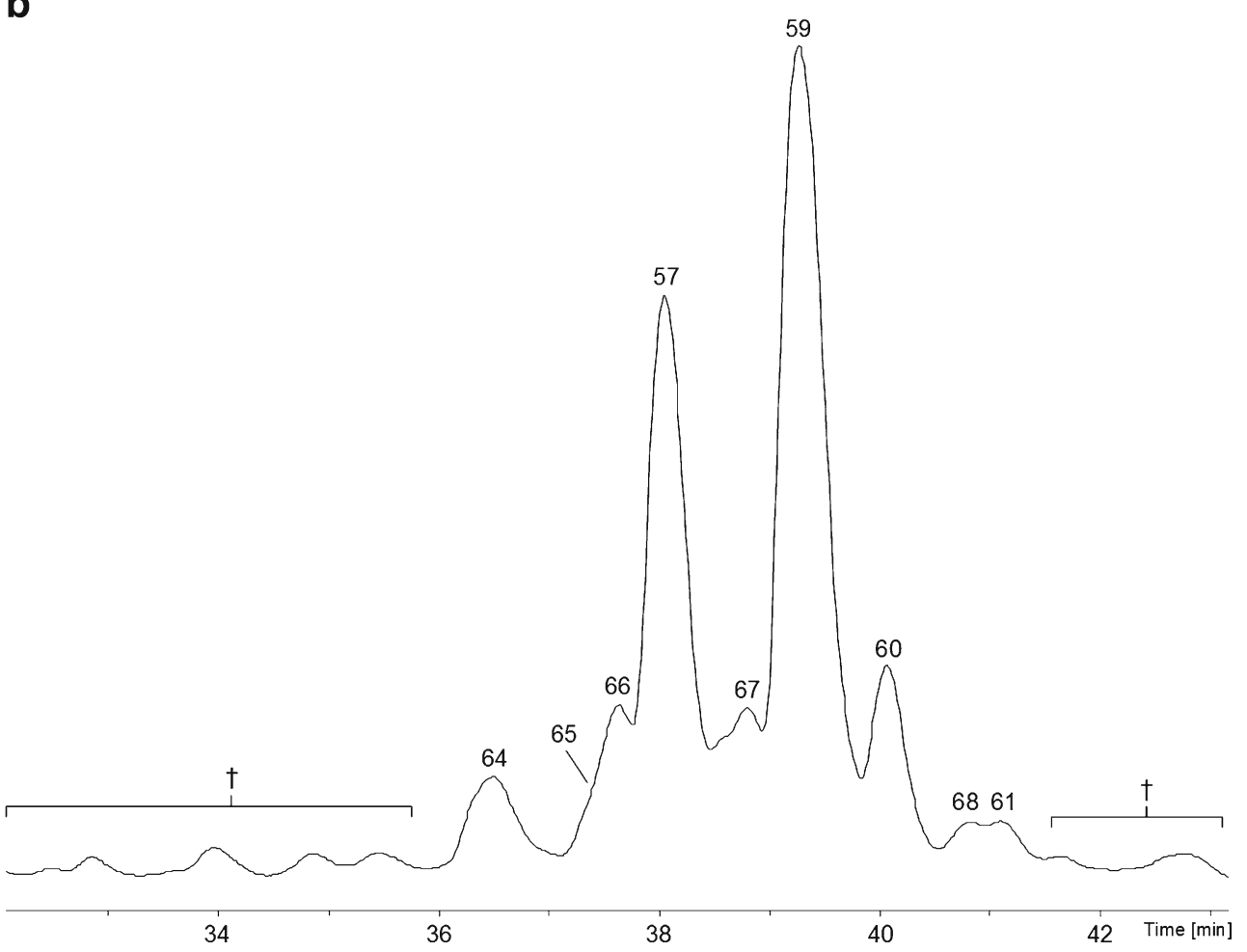




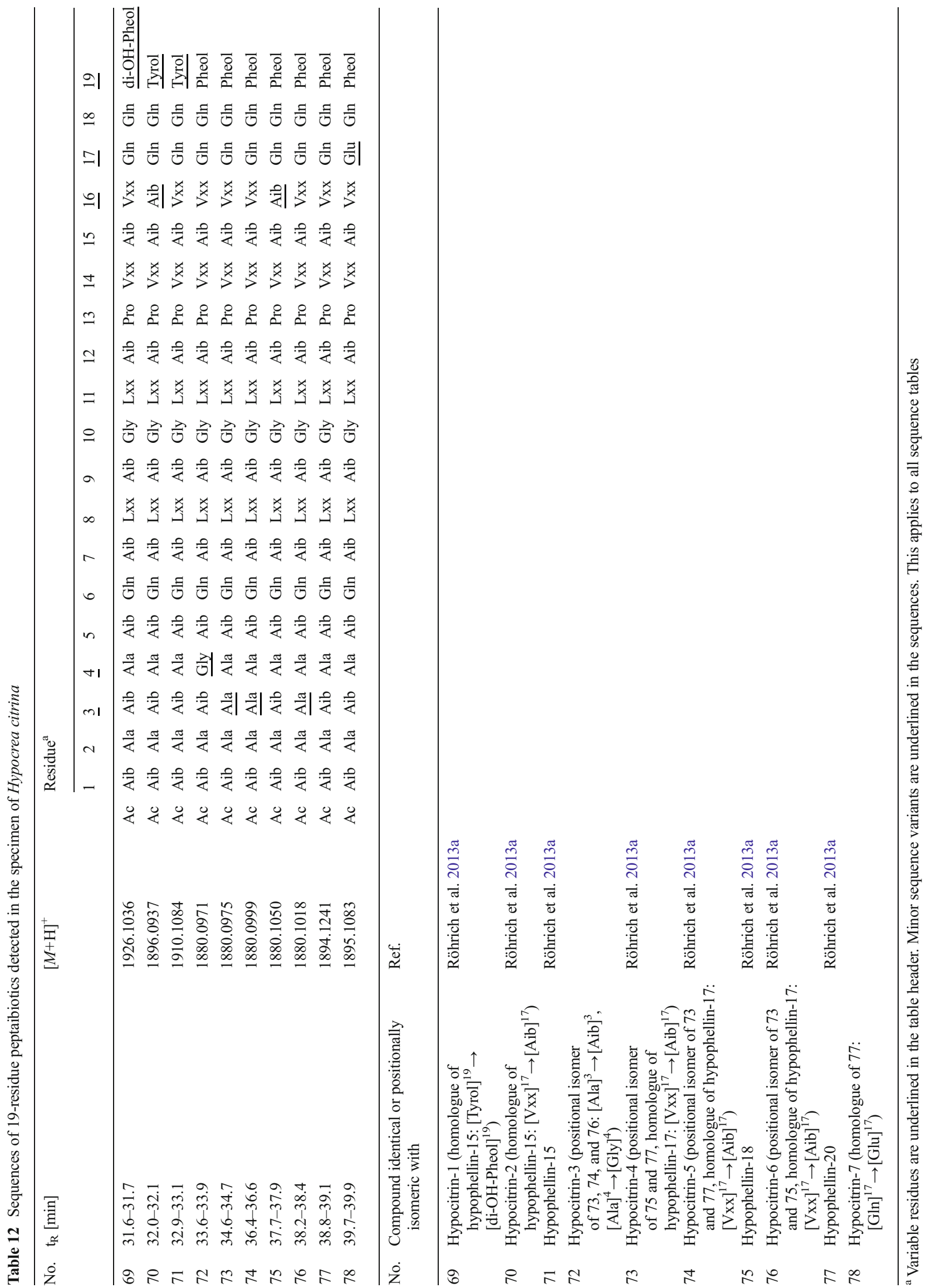


minutisporins 1-8 (Tables 10 and 11, Table S4a and S4b; Fig. 5a), resembling the recently described hypophellins (Röhrich et al. 2013a). Analysis of the plate culture (Fig. 5b) revealed that compounds 59-61 were recurrently isolated along with another five new 19-residue sequences, minutisporins 9-13 (compounds 64-68).

Screening of Hypocrea citrina. The specimen of H. citrina was shown to be a prolific producer of 19-residue peptaibols, compounds 69-78, of which seven are new, viz. compounds 69, 70, 72-74, 76, and 78. The names hypocitrins 1-7 were selected in order to avoid possible confusion with the mycotoxin citrinin and its derivatives. The remaining three were identified as hypophellin-15, -18 , and -20 , respectively (Röhrich et al. 2013a). Notably, compound 69, hypocitrin-1, exhibits a $C$-terminal substituent, which is novel to peptaibiotics, dihydroxyphenylalaninol (Table 12 and Table S5; Fig. 6). Compound 70, hypocitrin-2, a homologue of hypophellin-15 (compound 73), also terminates in Tyrol (Fig. 4). Due to exceptionally high background noise of unknown origin, the methanolic extract of the well-grown $H$. citrina plate culture could not be interpreted appropriately.

Screening of Hypocrea sulphurea. All three specimens of $H$. sulphurea were negatively screened for peptaibiotics. From two of them, plate cultures could be obtained; however, those were also screened negatively (data not shown).

Screening of Hypocrea parmastoi. Neither specimen, nor plate culture of $H$. parmastoi displayed the presence of peptaibiotics (data not shown).

Screening of specimens collected in the natural habitat(s) corroborated the distinguished importance of the genus Trichoderma/Hypocrea as the currently richest source of peptaibiotics. Five of the nine specimens were screened positively, and the results of this screening confirmed by the sequences obtained from screening of the plate cultures. Notably, 56 of the 78 peptaibiotics ( $72 \%$ ) detected represent new sequences.

Screening of $H$. voglmayrii and $H$. citrina revealed five peptaibols (compounds 37-39, 70, and 73) carrying a $C$-terminal Tyrol, a residue quite recently described for $H$. phellinicola (Röhrich et al. 2013a), which is considered comparatively rare. The additional substituent of the $C$-terminal Tyrol of voglmayrins 12-17 (compounds 46-51), which has tentatively been assigned as a prenyl or isoprenyl $\left(\mathrm{C}_{5} \mathrm{H}_{8}\right)$ residue, is hypothesised to be located at the $p$-hydroxy group. A regiospecific $O$-prenylation at the 4-position of the aromatic ring has recently been demonstrated for SirD (Zou et al. 2011), a tyrosine $O$ prenyltranferase (Kremer and $\mathrm{Li}$ 2010) catalysing the first pathway-specific step in the biosynthesis of the phytotoxin sirodesmin PL. The latter is produced by Leptosphaeria maculans (anamorph: Phoma lingam), the causal agent of blackleg of canola (Brassica napus). Recently, O-prenyltyrosine diketopiperazines have been described from Fusarium sp. and Penicillium crustosum (Guimarães et al. 2010).

Another notable structural element, dihydroxy-Pheol was found at the $C$-terminus of hypocitrin-1 (compound 69). While the presence of either Pheol or Tyrol may be assumed to originate from the relaxed substrate specificity in the terminal adenylate domain of the respective peptaibol synthetase, the direct incorporation of dihydroxy-Phe, presumably 3,4-dihydroxy-L-Phe (DOPA), is one possible biosynthetic route. Fungal tyrosinases are known to oxidise not only Tyr and various other monophenols, e.g. in the route to melanins, but also act on tyrosyl residues within peptides and proteins, leading to the formation of inter- and intra-molecular crosslinks (Selinheimo et al. 2007). Thus, Tyrol-containing peptaibols could be further oxidised by tyrosinases, and even
Fig. 6 Base-peak chromatograms (BPCs) of the specimen of $H$. citrina analysed with the micrOTOF-Q II. $\$$, co-eluting peptaibiotics, not sequenced

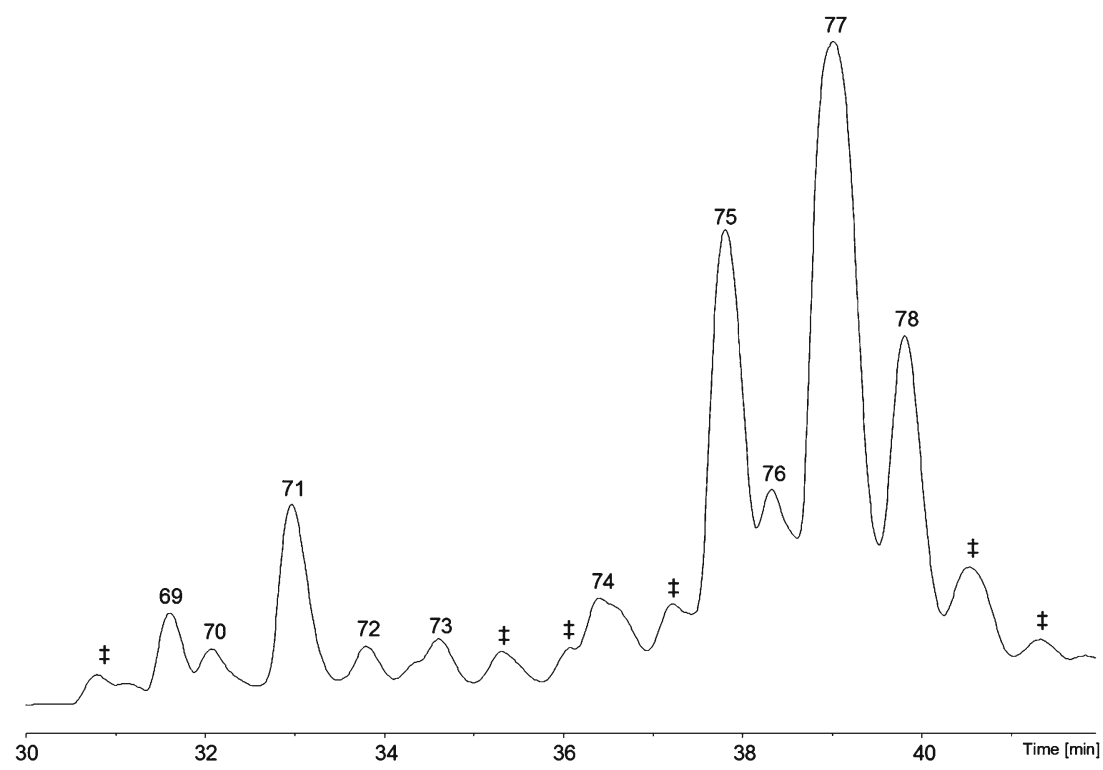


become attached to components of the fungal cell wall (Mattinen et al. 2008).

Considering the sequences of all species screened, including those of H. pulvinata and H. phellinicola, a general building scheme for those SF1-peptaibiotics can be given (Table 13):

As can be seen from above, all structural features (Röhrich et al. 2012) required for ion channel formation (Grigoriev et al. 2003), are present in the 17-, 18-, 19-, and 20-residue peptaibiotics sequenced. Multiple bioactivities of poreforming 20-residue SF1-peptaibiotics (Röhrich et al. 2013a) and of 11-residue SF4-peptaibiotics (Bobone et al. 2013; Röhrich et al. 2013b) have recently been compiled.

The results of our screening programme further extend the list of peptaibiotic-producing species of Trichoderma/Hypocrea compiled in Table 14. Most notably, the sequences of peptaibiotics produced by the freshly collected specimens are either identical to those found in the plate cultures, or represent at least - closely related homologues and positional isomers of the latter. Thus, our LC-MS/MS screening approach confirmed that all peptaibiotic-producing specimens and plate cultures obtained thereof represent one and the same species. Consequently, the same type (= subfamily) of peptaibiotics is produced both in the natural habitat and under artificial (= laboratory) conditions a fact, which is important for the application of Trichoderma formulations in biocontrol and integrated pest management schemes. A Trichoderma/Hypocrea species capable of producing peptaibiotics under the conditions of its natural habitat may defend its ecological niche more effectively compared to a non-producing species, as will be outlined below. At present, ca. $15 \%$ of the phylogenetically verified Trichoderma/Hypocrea species have been positively screened for peptaibiotics; however, it appears that the inventory of peptaibiotics of the remaining $85 \%$ is still waiting to be scrutinised by state-of-the-art bioanalytical particularly mass spectrometric - methods. Of approximately 130 Trichoderma/Hypocrea species pre-screened by LC/ HRMS (Nielsen et al. 2011), ca. 60 were found to produce peptaibiotics ${ }^{8}$. Thus, the production of peptaibiotics in the natural habitat seems to be independent of the habitat preference, i.e. mycoparasitism vs. saprotrophy (Chaverri and Samuels 2013), but neither predictable per se nor universal.

Given that peptaibiotics are readily biosynthesised in the natural habitat of the producers, they could significantly contribute to the complex interactions of phytoprotective Trichoderma species, which are used in commercial or semi-commercial biocontrol agents (BCAs) against plant pathogenic fungi (Harman et al. 2004; Viterbo et al. 2007; Vinale et al. 2008a, b). Examples of successful biocontrol approaches using Trichoderma strains include 'Tricovab', a Brazilian formulation recently approved (Anonymous 2012) for integrated management of Crinipellis

\footnotetext{
${ }^{8}$ Nielsen KF, Samuels GJ (2013) unpublished results.
}

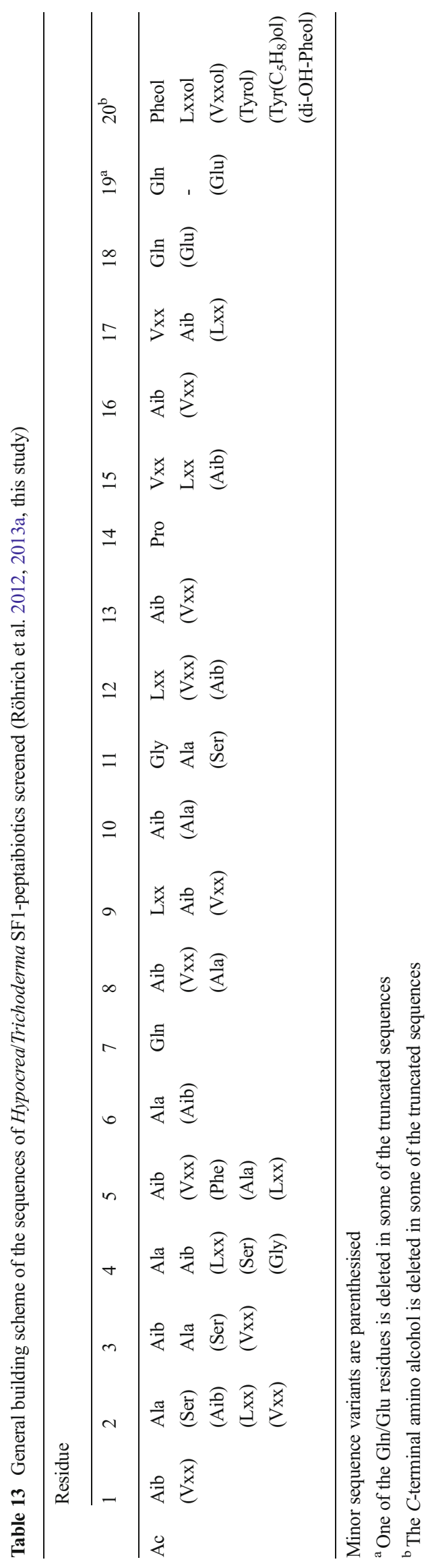


Table 14 Phylogenetically verified peptaibiotic-producing strains and species of Trichoderma/Hypocrea. NB: Species and strains for which only MALDI-TOF-MS screening data have been published are not considered for inclusion

\begin{tabular}{|c|c|c|c|}
\hline Species & $\begin{array}{c}\text { Positively screened } \\
\text { strains }\end{array}$ & Peptaibiotics found & References \\
\hline \multirow[t]{5}{*}{ T. arundinaceum } & $\begin{array}{l}\text { CBS } 119575 \\
\text { (ex-type) }\end{array}$ & $\begin{array}{l}\text { alamethicins F30 } \\
\text { alamethicins F50 } \\
\text { trichobrevins A } \\
\text { trichobrevins B } \\
\text { trichocompactins } \\
\text { trichoferin A }\end{array}$ & Degenkolb et al. 2008 \\
\hline & $\begin{array}{l}\text { CBS } 119576 \\
(=\mathbf{A T C C ~ 9 0 2 3 7 )})^{\mathbf{a}}\end{array}$ & $\begin{array}{l}\text { trichobrevins A } \\
\text { trichobrevins B } \\
\text { alamethicins F30 } \\
\text { trichocompactins } \\
\text { trichoferins }\end{array}$ & 1 \\
\hline & CBS 119577 & $\begin{array}{l}\text { trichocryptins B } \\
\text { trichobrevins A } \\
\text { alamethicins F30 } \\
\text { trichobrevins B } \\
\text { trichocompactins } \\
\text { trichoferin A }\end{array}$ & Degenkolb et al. $2006 \mathrm{~b}$ \\
\hline & CBS 121153 & $\begin{array}{l}\text { alamethicins F30 } \\
\text { alamethicins F50 } \\
\text { trichobrevins A } \\
\text { trichobrevins B } \\
\text { trichocompactins } \\
\text { trichoferin A }\end{array}$ & Degenkolb et al. 2008 \\
\hline & $\begin{array}{l}\text { CBS } 123793 \\
\text { (= NRRL 3199) }\end{array}$ & $\begin{array}{l}\text { alamethicins F30 } \\
\text { alamethicins F50 } \\
\text { trichobrevins A } \\
\text { trichobrevins B } \\
\text { trichocompactins } \\
\text { trichoferins }\end{array}$ & $\begin{array}{l}\text { Kirschbaum et al. 2003; } \\
\text { Psurek et al. 2006; } \\
\text { Degenkolb et al. } 2006 \text { b, } \\
\text { Degenkolb et al. } 2008\end{array}$ \\
\hline \multirow[t]{6}{*}{ T. brevicompactum } & $\begin{array}{l}\text { CBS } 109720 \\
\text { (= DAOM } 231232, \\
\text { ex-type) }\end{array}$ & $\begin{array}{l}\text { alamethicins F30 } \\
\text { trichocryptins A } \\
\text { trichocryptins B } \\
\text { trichocompactins }\end{array}$ & Degenkolb et al. $2006 b$ \\
\hline & CBS 112444 & $\begin{array}{l}\text { alamethicins F30 } \\
\text { trichocompactins } \\
\text { trichocryptins A } \\
\text { trichocryptins B } \\
\text { trichoferin A }\end{array}$ & 1 \\
\hline & CBS 112446 & alamethicins F30 & Degenkolb et al. 2008 \\
\hline & CBS 112447 & $\begin{array}{l}\text { alamethicins F50 } \\
\text { trichocompactins } \\
\text { trichocryptins A } \\
\text { trichocryptins B } \\
\text { trichoferins }\end{array}$ & 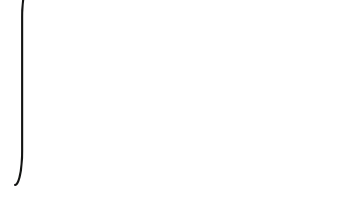 \\
\hline & CBS 119569 & alamethicins F30 & Degenkolb et al. $2006 \mathrm{~b}$ \\
\hline & CBS 119570 & $\begin{array}{l}\text { trichocryptins A } \\
\text { trichocompactins }\end{array}$ & \\
\hline
\end{tabular}

(syn. Moniliophthora) perniciosa, the causal agent of Witches' broom of cacao (Pomella et al. 2007; Loguercio et al. 2009; Medeiros et al. 2010). Notably, 'Tricovab' contains a peptaibiotic-producing strain (Degenkolb et al. 2006a) of the hyperparasitic endophyte Trichoderma stromaticum. Moreover, the in vivo-detection of peptaibiotics corroborates the recently demonstrated pro-apoptotic in vitro- activities of the 19-residue peptaibols trichokonin $\mathrm{VI}^{9}$ (Huang et al. 1995) from Trichoderma pseudokoningii SMF2

\footnotetext{
${ }^{9}$ Trichokonin VI is identical to gliodeliquescin A that has been isolated from Gliocladium deliquescens NRRL 1086 (Brückner et al. 1988) and not from NRRL 3091 (Brückner and Przybylski 1984). According to phylogenetic data, $G$. deliquescens NRRL 1086 (= CBS 228.48=ATCC 10097) was re-identified as G. viride, see (www.straininfo.net/strains/260309).
} 
Table 14 (continued)

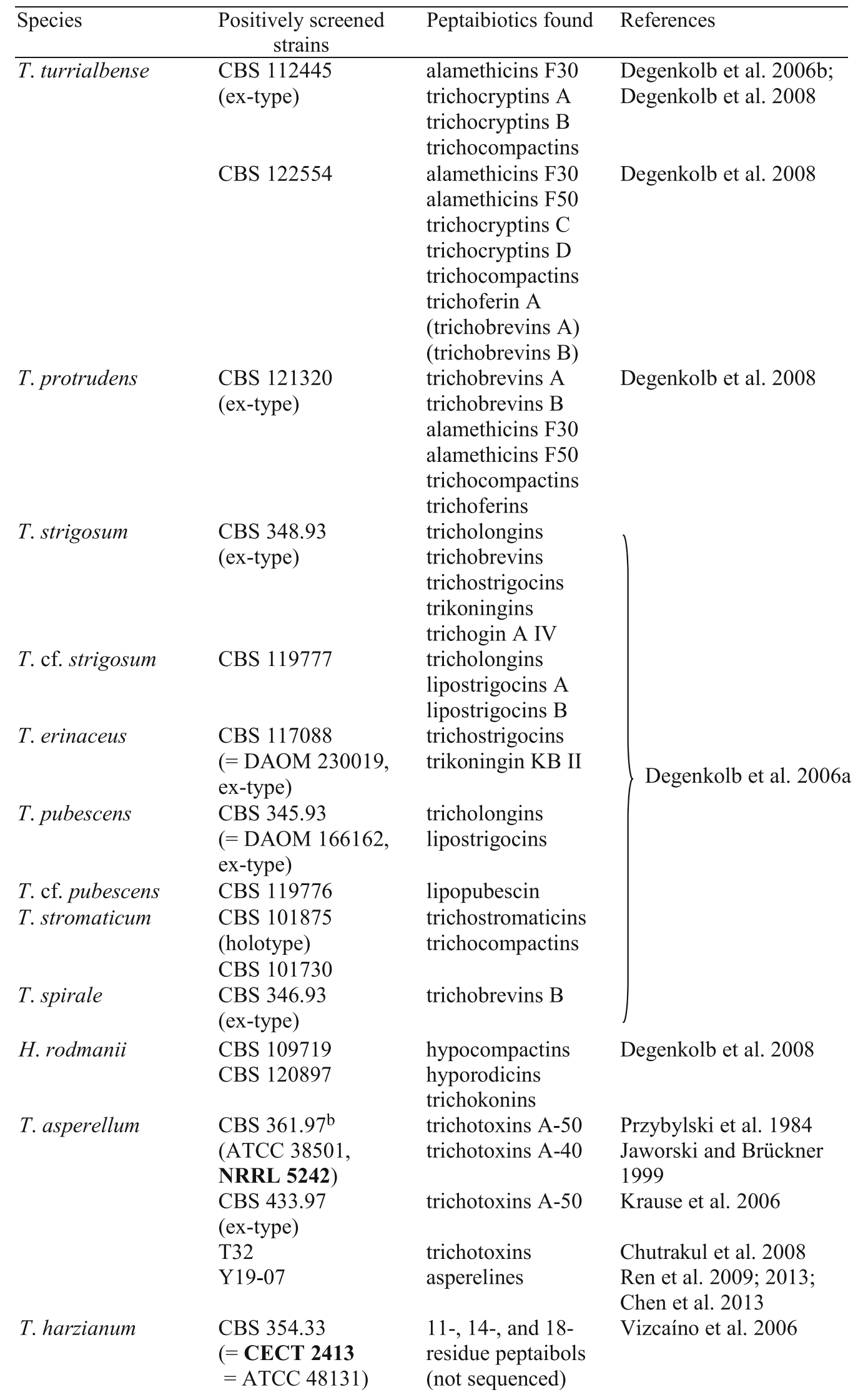


Table 14 (continued)

\begin{tabular}{|c|c|c|c|}
\hline Species & $\begin{array}{c}\text { Positively screened } \\
\text { strains }\end{array}$ & Peptaibiotics found & References \\
\hline T. cf. harzianum & $\begin{array}{l}\text { CBS } 130670^{c} \\
\text { (ATCC 90200, } \\
\text { NRRL 5243) }\end{array}$ & trichovirins II & Jaworski et al. 1999 \\
\hline \multirow[t]{2}{*}{ T. virens } & Tv29-8 & $\begin{array}{l}\text { trichorzins }(18- \\
\text { residue }\end{array}$ & Wiest et al. 2002 \\
\hline & & $\begin{array}{l}\text { peptaibols), } \\
11 \text { - and 14-residue } \\
\text { peptaibols }\end{array}$ & Mukherjee et al. 2011 \\
\hline \multirow[t]{3}{*}{ T. polysporum } & TMI 60146 & trichopolyns & $\begin{array}{l}\text { Fuji et al. 1978; Fujita et } \\
\text { al. 1981; Iida et al. } 1999\end{array}$ \\
\hline & & trichosporins-B & $\begin{array}{l}\text { Fujita et al. 1988, Iida et } \\
\text { al. 1990; Iida et al. } 1993\end{array}$ \\
\hline & FKI-4452 & trichosporins-B & Iwatsuki et al. 2010 \\
\hline T.reesei & CBS 392.92 & paracelsins & Brückner and Graf 1983; \\
\hline (H. jecorina) & $\begin{array}{l}\text { (ATCC 2692, } \\
\text { QM 9414) }\end{array}$ & & Brückner et al. 1984 \\
\hline \multirow[t]{2}{*}{ T. parareesei } & C.P.K. 618 & hypojecorins-A & Degenkolb et al. 2012 \\
\hline & C.P.K. 665 & $\begin{array}{l}\text { hypojecorins-B } \\
\text { paracelsins }\end{array}$ & \\
\hline T. saturnisporum & $\begin{array}{l}\text { CBS } 330.70 \\
\text { (ex-type) }\end{array}$ & paracelsin $\mathrm{E}$ & Ritieni et al. 1995 \\
\hline \multirow[t]{8}{*}{ T. atroviride } & IFO $31288^{d}$ & $\begin{array}{l}\text { hypomurocins A } \\
\text { hypomurocins B }\end{array}$ & Becker et al. 1997 \\
\hline & $\begin{array}{l}\text { CBS } 391.92^{\mathrm{e}} \\
(=\text { ATCC 36042) }\end{array}$ & trichorzianins & El Hajji et al. 1987 \\
\hline & $\begin{array}{l}\text { ATCC } 74058^{\mathrm{f}} \\
(=\mathrm{P} 1) \text { and mutants } \\
\text { thereof }\end{array}$ & $\begin{array}{l}\text { trichorzianins, } \\
\text { trichoatrokontins }\end{array}$ & $\begin{array}{l}\text { Pócsfalvi et al. 1998; } \\
\text { Stoppacher et al. 2007, } \\
2008\end{array}$ \\
\hline & MMS 639 & unprecedented & Carroux et al. 2013 \\
\hline & MMS 925 & 17-residue & \\
\hline & MMS 927 & peptaibiotics and & \\
\hline & MMS 1295 & 19-residue & \\
\hline & MMS 1513 & peptaibols & \\
\hline T. atroviride & NF16 & $\begin{array}{l}\text { new and recurrent } \\
\text { trichorzianins }\end{array}$ & Panizel et al. 2013 \\
\hline \multirow[t]{2}{*}{ T. citrinoviride } & IMI $91968^{g}$ & trichoaureocins & $\begin{array}{l}\text { Jaworski and Brückner } \\
\text { 2001a }\end{array}$ \\
\hline & $\mathbf{S 2 5}$ & $\begin{array}{l}\text { 20-residue } \\
\text { peptaibols }\end{array}$ & Maddau et al. 2009 \\
\hline \multirow[t]{13}{*}{ T. longibrachiatum } & $\begin{array}{l}\text { DAOM } 234100 \\
(=\text { MMS 151) }\end{array}$ & $\begin{array}{l}\text { 11-residue } \\
\text { trichobrachins }\end{array}$ & $\begin{array}{l}\text { Mohamed-Benkada et al. } \\
\text { 2006; Ruiz et al. } 2007\end{array}$ \\
\hline & Thb & 11- and 20-residue & Mikkola et al. 2012 \\
\hline & Thd & trilongins & \\
\hline & $\begin{array}{l}\text { CNM-CM } 2171 \\
(=\text { C P K 1696) }\end{array}$ & & \\
\hline & CNM-CM 2277 & & \\
\hline & $(=$ C.P.K. 2277) & & \\
\hline & IMI 291014 & & \\
\hline & $(=$ C.P.K. 1303) & & \\
\hline & CECT 2412 & & \\
\hline & $(=$ C.P.K. 2062) & & \\
\hline & CECT 20105 & & \\
\hline & $\begin{array}{l}\text { (= C.P.K. } 1698 \\
=\text { IMI } 297702)\end{array}$ & & \\
\hline & = IMI 297702) & & \\
\hline
\end{tabular}


Table 14 (continued)

\begin{tabular}{|c|c|c|c|}
\hline Species & $\begin{array}{c}\text { Positively screened } \\
\text { strains }\end{array}$ & Peptaibiotics found & References \\
\hline $\begin{array}{l}T . \text { ghanense } \\
\text { (syn. } T . \\
\text { parceramosum) }\end{array}$ & CBS 936.69 & trichobrachins & $\begin{array}{l}\text { Brückner et al. } 1993 ; \\
\text { Krause et al. } 2007\end{array}$ \\
\hline H. pulvinata & $\begin{array}{l}\text { CBS } 133228 \\
\text { CBS } 133229 \\
\text { CBS } 133230\end{array}$ & hypopulvins & Röhrich et al. 2012 \\
\hline $\begin{array}{l}\text { H. phellinicola } \\
\text { (ex-type) }\end{array}$ & CBS 119283 & hypophellins & Röhrich et al. 2013 \\
\hline H. peltata & Not deposited & hypelcins & $\begin{array}{l}\text { Fujita et al. 1984; } \\
\text { Matsuura et al. 1993, } \\
1994\end{array}$ \\
\hline $\begin{array}{l}\text { T. deliquescens } \\
(=G . \text { deliquescens } \\
=G . \text { viride })^{\mathrm{j}}\end{array}$ & $\begin{array}{l}\text { CBS } 228.48 \\
(=\text { ATCC } 10097)\end{array}$ & gliodeliquescin $\mathrm{A}$ & $\begin{array}{l}\text { Brückner and Przybylski } \\
1984\end{array}$ \\
\hline $\begin{array}{l}\text { T. flavofuscum } \\
\text { (ex-type; syn. } T \text {. } \\
\text { virens: Chaverri } \\
\text { and Samuels [2003]) }\end{array}$ & $\begin{array}{l}\text { CBS } 248.59 \\
(=\text { ATCC } 13398 \\
=\text { DSM } 3500 \\
=\text { IMI } 100714)\end{array}$ & trichofumins & Berg et al. 2003 \\
\hline $\begin{array}{l}\text { T. asperellum } \\
\text { T. aggressivum var. } \\
\text { europaeum } \\
\text { T. inhamatum } \\
\text { H. dichromospora } \\
\text { H. vinosa } \\
\text { H. semiorbis } \\
\text { H. citrina } \\
\text { (syn. H. lactea) } \\
\text { H. nigricans }\end{array}$ & $\begin{array}{l}\text { CBS } 433.97 \\
\text { CBS } 100526 \\
\text { CBS } 345.96 \\
\text { CBS } 337.69 \\
\text { CBS } 247.63 \\
\text { CBS } 244.63 \\
\text { CBS } 853.70 \\
\text { MUCL } 28439\end{array}$ & \multicolumn{2}{|c|}{$\begin{array}{l}\text { only partial } \\
\text { sequences were } \\
\text { given, for } \\
\text { comments on } \\
\text { sequencing/putative } \\
\text { identification of } \\
\text { peptaibiotics, see } \\
\text { Krause et al. (2006) }\end{array}$} \\
\hline H. schweinitzii & ICMP 5421 & $\begin{array}{l}\text { screened positive } \\
\text { for peptidic Aib } \\
\text { and Iva } \\
\text { screened positive } \\
\text { for peptidic Aib }\end{array}$ & Brückner et al. 1991 \\
\hline
\end{tabular}

\footnotetext{
${ }^{a}$ Accession numbers under which the peptaibiotic-producing strain was first published are highlighted in bold.

${ }^{\mathrm{b}}$ Originally misidentified as $T$. viride (Hou et al. 1972).

${ }^{c}$ Originally misidentified as T. viride (Hou et al. 1972).

${ }^{\mathrm{d}}$ Originally misidentified as H. muroiana, for taxonomic revision see Samuels et al. (2006).

e Originally misidentified as T. harzianum (el Hajji et al. 1987), for reidentification see Kuhls et al. (1996).

${ }^{\mathrm{f}}$ Originally misidentified as $T$. harzianum.

g Originally misidentified as T. aureoviride; data taken from http://www.herbimi.info/herbimi/specimen.htm?imi $=91968$

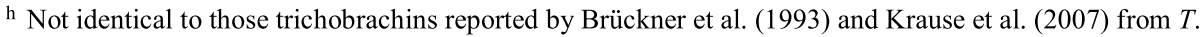
ghanense CBS 936.69.

${ }^{i}$ Originally misidentified as $T$. longibrachiatum.

${ }^{\mathrm{j}}$ For taxonomic recombination of G. deliquescens, the anamorph of H. lutea, see Jaklitsch (2011).
}

towards plant fungal pathogens such as Fusarium oxysporum (Shi et al. 2012).

The value of peptaibiotics for chemotaxonomy of Trichoderma/Hypocrea has scarcely been scrutinised in the past (Neuhof et al. 2007; Degenkolb et al. 2008). To exhaustively answer this question, a larger number of strains, belonging to recently described species, are required to be included in an LC-MS/MS-based study 
aimed at analysing the peptaibiome of strains and species within different clades of Trichoderma/Hypocrea. However, statements on peptaibiotic production by a particular Trichoderma/Hypocrea species must always be treated with great caution as they are highly habitat-, isolate-, and/or cultivation-dependent. Furthermore, 'peptaibol subfamilies' were introduced at a time when the total number of peptaibiotics described did not exceed 200 (Chugh and Wallace 2001) - less than a sixth of the currently known sequences. Notably, the additional 1,000-1,100 individual peptaibiotics published since then exhibit both new building schemes and constituents. This issue becomes even more complex as 'peptaibol subfamilies' were published when phylogenetic methods have not yet been recognised as an indispensable tool in fungal taxonomy. Thus, a considerable number of peptaibiotics, the sequences of which have been elucidated correctly, cannot be linked to an unambiguously identified producer that is deposited in a publicly accessible culture collection. These facts illustrate the urgent need to reconsider the classification into the nine subfamilies - a task that has to be completed before the aforementioned study can be performed.

Currently, any approach for a peptaibiotics-based chemotaxonomy of Trichoderma/Hypocrea must be regarded as extremely complicated - even within a defined clade -, because $i$ ) peptaibiotics only represent one single class of secondary metabolites produced by Trichodermal Hypocrea, ii) most of the producers reported in literature have never been deposited appropriately, and iii) the persistently high degree of misidentification makes any comparison between members of different clades problematic and challenging. This is illustrated by the following examples (references are compiled in Table 14):

i) The 20-residue alamethicins (ALMs) have hitherto been found in four species belonging to the Brevicompactum clade of Trichoderma; however, it is not yet possible to estimate if the $\mathrm{Pro}^{2}$ residue of the ALMs could be regarded as a structurally highly conserved position, comparable to the $\mathrm{Pro}^{14}$ residue. Chemotaxonomy of the Brevicompactum clade encompassed the comparison of hydrophobins, peptaibiotics, and lowmolecular weight secondary metabolites, including simple trichothecene-type mycotoxins.

ii) The 18-residue trichotoxins (TXT) A-50 and A-40, for example, have been obtained from Trichoderma asperellum NRRL 5242, whereas Trichoderma asperellum Y 19-07 did not produce TXTs but 9- and 10-residue peptaibols instead (and vice versa).

iii) Trichoderma citrinoviride strains S 25 and IMI 91968 are rich sources of 20-residue peptaibols of the paracelsin/ saturnisporin/trichocellin/suzukacillin/trichoaureocin- type. These are the only two strains of $T$. citrinoviride that have been investigated for peptaibiotics. Hypocrea schweinitzii ICMP 5421, which has also been verified phylogenetically (Réblová and Seifert 2004), had only been screened positive for Aib by GC/MS; but - to the best of the authors' knowledge - specimens of that species have never been investigated for its inventory of peptaibiotics. Parcelsins, which have been isolated from T. reesei $\mathrm{QM} 9414$, are also produced by a member of the Longibrachiatum clade. However, the producer of saturnisporin (T. saturnisporum MNHN 903578: Rebuffat et al. 1993) has never been made publicly available, nor has its identity been verified phylogenetically. The producers of both trichocellins and suzukacillins A (Krause et al. 2006b) have not been deposited in a publicly available culture collection; thus, their identification as $T$. 'viride' is highly questionable.

iv) T. flavofuscum CBS 248.59 is the only species of Trichoderma/Hypocrea, which produces 13-residue sequences - notably trichofumins $\mathrm{C}$ and D are the only two peptaibols of that chain length reported to date. They display the rare Gln-Gln motif in positions 5 and 6. Looking at the sequences, their biosynthesis seems to be distantly related to that one of trichofumins $\mathrm{A}$ and $\mathrm{B}$ (and positional isomers thereof). The latter are 11residue SF4-peptaibols and widespread amongst Trichoderma/Hypocrea species.

v) T. virens strain Tv29-8 produces common 11- and 14residue peptaibols, and it is the only phylogenetically verified source of 18-residue peptaibols of the trichorzintype.

However, the results of our LC-MS/MS screening are also of interest for analysis of environmental samples as well as extraterrestrial materials such as carbonaceous meteorites as their contamination by propagules of soil- or airborne peptaibiotic-producing fungi has to be taken into account (Brückner et al. 2009; Elsila et al. 2011).

To sum up, production of peptaibiotics may generally be regarded as a sophisticated ecological adaptation for the producing fungus providing it with an obvious advantage over non-producing fungal and other competitors. This group of 'chemical weapons' in their 'armoury' may effectively assist a remarkable number of strains currently identified as belonging to ca. 30 Trichoderma/Hypocrea species in colonising and defending their ecological niches.

Acknowledgments This study was supported by the Hessian Ministry for Science and Art by a grant from the LOEWE-Schwerpunkt 'Insect Biotechnology' to Andreas Vilcinskas. DTU acknowledges the grant from the Danish Research Council (FI 2136-08-0023) for the maXis QTOF system, and MYCORED (EC KBBE-2007-222690-2) for supporting Anita Iversen. Walter M. Jaklitsch gratefully acknowledges 
the support by the Austrian Science Fund (project P22081-B17). Thanks to James L. Swezey (USDA-ARS, NCAUR) for his comments on two peptaibol-producing Trichoderma strains, NRRL 5242 and NRRL 5243. Hans Brückner gratefully acknowledges his position as a Visiting Professor at King Saud University (Riyadh, Kingdom of Saudi Arabia).

Open Access This article is distributed under the terms of the Creative Commons Attribution License which permits any use, distribution, and reproduction in any medium, provided the original author(s) and the source are credited.

\section{References}

Adelin E, Servy C, Martin M-T, Arcile G, Iorga BI, Retailleau P, Bonfill M, Ouazzani J (2014) Bicyclic and tetracyclic diterpenes from a Trichoderma symbiont of Taxus baccata. Phytochemistry 97:55-61

Anonymous, Novembro 2011/Fevereiro 2012. Ministério da agricultura, pecuária e abastecimento (MAPA)/comissão executivado plano da lavoura cacaueira (CEPLAC). Ministério da agricultura aprovou registro do tricovab para combate à vassoura-de-bruxa. Jornal de Cacau 6:5

Atanasova L, Druzhinina IS, Jaklitsch WM (2013) Two hundred Trichoderma species recognized based on molecular phylogeny. In: Mukherjee PK, Singh US, Horwitz BA, Schmoll M, Mukherjee M (eds) Trichoderma: biology and applications. CABI, Nosworthy Way, Wallingford, Oxon, UK, pp 10-42

Auvin-Guette C, Rebuffat S, Prigent Y, Bodo B (1992) Trichogin AIV, an 11-residue lipopeptaibol from Trichoderma longibrachiatum. J Am Chem Soc 114:2170-2174

Ayers S, Ehrmann BM, Adcock AF, Kroll DJ, Carcache de Blanco EJ, Shen Q, Swanson SM, Falkinham JO III, Wani MC, Mitchell SM, Pearce CJ, Oberlies NH (2012) Peptaibols from two unidentified fungi of the order Hypocreales with cytotoxic, antibiotic, and anthelmintic activities. J Pept Sci 18:500-510

Becker D, Kiess M, Brückner H (1997) Structures of peptaibol antibiotics hypomurocin A and B from the ascomycetous fungus Hypocrea muroiana Hino et Katsumoto. Liebigs Ann Recueil 767-772

Berg A, Grigoriev PA, Degenkolb T, Neuhof T, Härtl A, Schlegel B, Gräfe U (2003) Isolation, structure elucidation and biological activities of trichofumins A, B, C and D, new 11 and 13mer peptaibols from Trichoderma sp. HKI 0276. J Pept Sci 9:810-816

Bobone S, Gerelli Y, De Zotti M, Bocchinfuso G, Farrotti A, Orioni B, Sebastiani F, Latter E, Penfold J, Senesi R, Formaggio F, Palleschi A, Toniolo C, Fragneto G, Stella L (2013) Membrane thickness and the mechanism of action of the short peptaibol trichogin GA IV. Biochim Biophys Acta 1828:1013-1024

Brückner H, Graf H (1983) Paracelsin, a peptide antibiotic containing $\alpha$ aminoisobutyric acid, isolated from Trichoderma reesei Simmons. Part A Experientia 39:528-530

Brückner H, Przybylski M (1984) Methods for the rapid detection, isolation and sequence determination of "peptaibols" and other Aib-containing peptides of fungal origin. I. Gliodeliquescin A from Gliocladium deliquescens. Chromatographia 19:188-199

Brückner H, Graf H, Bokel M (1984) Paracelsin; characterization by NMR spectroscopy and circular dichroism, and hemolytic properties of a peptaibol antibiotic from the cellulolytically active mold Trichoderma reesei. Part B Experientia 40:1189-1197

Brückner H, Wunsch P, Kussin C (1988) Production of polypeptide antibiotics by molds of the genus Gliocladium. In: Aubry A, Marraud M, Vitoux B (eds) Second forum on peptides, vol 174. Colloque INSERM/John Libbey Eurotext, London \& Paris, pp 103-106

Brückner H, Maisch J, Reinecke C, Kimonyo A (1991) Use of $\alpha$ aminoisobutyric acid and isovaline as marker amino acids for the detection of fungal polypeptide antibiotics. Screening of Hypocrea. Amino Acids 1:251-257

Brückner H, Kripp T, Kieß M (1993) Polypeptide antibiotics trichovirin and trichobrachin: Sequence determination and total synthesis. In: Brandenburg D, Ivanov V, Voelter W (eds) Chemistry of Peptides and Proteins; Proceedings of the 7th USSR-FRG Symposium Chemistry of Peptides and Proteins', Dilizhan, USSR, 1989, and in 'Chemistry of Peptides and Proteins; Proceedings of the 8th USSR-FRG Symposium Chemistry of Peptides and Proteins, Aachen, FRG, 1991', Mainz Verlag, Aachen, 1993, DWI Reports, vol. $112 \mathrm{~A}+\mathrm{B}$, pp 357-373

Brückner H, Becker D, Gams W, Degenkolb T (2009) Aib and Iva in the biosphere: neither rare nor necessarily extraterrestrial. Chem Biodivers 6:38-56

Carroux A, van Bohemen A-I, Roullier C, Robiou du Pont T, Vansteelandt M, Bondon A, Zalouk-Vergnoux A, Pouchus YF, Ruiz N (2013) Unprecedented 17-residue peptaibiotics produced by marine-derived Trichoderma atroviride. Chem Biodivers 10: $772-786$

Chaverri P, Samuels GJ (2003) Hypocrea/Trichoderma (Ascomycota, Hypocreales, Hypocreaceae): species with green ascospores. Stud Mycol 48:1-116

Chaverri P, Samuels GJ (2013) Evolution of habitat preference and nutrition mode in acosmopolitan fungal genus with evidence of interkingdom host jumps and major shifts in ecology. Evolution 67:2823-2837

Chaverri P, Gazis RO, Samuels GJ (2011) Trichoderma amazonicum, a new endophytic species on Hevea brasiliensis and H. guianensis from the Amazon basin. Mycologia 103:139-151

Chen L, Zhong P, Pan J-R, Zhou K-J, Huang K, Fang Z-X, Zhang Q-Q (2013) Asperelines $G$ and $H$, two new peptaibols from the marinederived fungus Trichoderma asperellum. Heterocycles 87:645-655

Chugh JK, Wallace BA (2001) Peptaibols: models for ion channels. Biochem Soc Trans 29:565-570

Chutrakul C, Alcocer M, Bailey K, Peberdy JF (2008) The production and characterisation of trichotoxin peptaibols by Trichoderma asperellum. Chem Biodivers 5:1694-1706

Degenkolb T, Brückner H (2008) Peptaibiomics: towards a myriad of bioactive peptide containing $\mathrm{C}^{\alpha}$-dialkylamino acids? Chem Biodivers 5:1817-1843

Degenkolb T, Gräfenhan T, Berg A, Nirenberg HI, Gams W, Brückner H (2006a) Peptaibiomics: screening for polypeptide antibiotics (peptaibiotics) from plant-protective Trichoderma species. Chem Biodivers 3:593-610

Degenkolb T, Gräfenhan T, Nirenberg HI, Gams W, Brückner H (2006b) Trichoderma brevicompactum complex: Rich source of novel and recurrent plant-protective polypeptide antibiotics (peptaibiotics). J Agric Food Chem 54:7047-7061

Degenkolb T, Dieckmann R, Nielsen KF, Gräfenhan T, Theis C, Zafari D, Chaverri P, Ismaiel A, Brückner H, von Döhren H, Thrane U, Petrini O, Samuels GJ (2008) The Trichoderma brevicompactum clade: a separate lineage with new species, new peptaibiotics, and mycotoxins. Mycol Prog 7:177-219

Degenkolb T, Karimi Aghcheh R, Dieckmann R, Neuhof T, Baker SE, Druzhinina IS, Kubicek CP, Brückner H, von Döhren H (2012) The production of multiple small peptaibol families by single 14-module peptide synthetases in Trichoderma/Hypocrea. Chem Biodivers 9: 499-535

Ding G, Chen L, Chen A, Tian X, Chen X, Zhang H, Chen H, Liu XZ, Zhang Y, Zou ZM (2012) Trichalasins C and D from the plant endophytic fungus Trichoderma gamsii. Fitoterapia 83: $541-544$

Ding G, Wang H, Li L, Song B, Chen H, Zhang H, Liu X, Zou Z (2014) Trichodermone, a spiro-cytochalasan with a tetracyclic nucleus $(7 / 5 /$ 6/5) skeleton from the plant endophytic fungus Trichoderma gamsii. J Nat Prod 77:164-167 
el Hajji M, Rebuffat S, Lecommaneur D, Bodo B (1987) Isolation and sequence determination of trichorzianines $\mathrm{A}$, antifungal peptides from Trichoderma harzianum. Int J Pept Prot Res 29:207-215

Elsila JE, Callahan MP, Glavin DP, Dworkin JP, Brückner H (2011) Distribution and stable isotopic composition of amino acids from fungal peptaibiotics: assessing the potential for meteoritic contamination. Astrobiology 11:123-133

Figueroa M, Raja H, Falkinham JO III, Adcock AF, Kroll DJ, Wani MC, Pearce CJ, Oberlies NH (2013) Peptaibols, tetramic acid derivatives, isocoumarins, and sesquiterpenes from a Bionectria sp. (MSX 47401). J Nat Prod 76:1007-1015

Fuji K, Fujita E, Takaishi Y, Fujita T, Arita I, Komatsu M, Hiratsuka N (1978) New antibiotics, trichopolyns A and B: isolation and biological activity. Experientia 34:237-239

Fujita T, Takaishi Y, Okamura A, Fujita E, Fuji K, Hiratsuka N, Komatsu M, Arita I (1981) New peptide antibiotics, trichopolyns I and II, from Trichoderma polysporum. J Chem Soc Chem Comm 585-587

Fujita T, Takaishi Y, Ogawa T, Tokimoto K (1984) Fungal metabolites. 1. Isolation and biological activities of hypelcins A and B (growth inhibitors against Lentinus edodes) from Hypocrea peltata. Chem Pharm Bull 32:1822-1828

Fujita T, Iida A, Uesato S, Takaishi Y, Shingu T, Saito M, Morita M (1988) Structural elucidation of trichosporin-B-Ia, IIIa, IIId and V from Trichoderma polysporum. J Antibiot 41:814-818

Gams W, Baral HO, Jaklitsch WM, Kirschner R, Stadler M (2012) Clarifications needed concerning the new Article 59 dealing with pleomorphic fungi. IMA Fungus 3:175-177

Grigoriev PA, Schlegel B, Kronen M, Berg A, Härtl A, Gräfe U (2003) Differences in membrane pore formation by peptaibols. J Pept Sci 9: 763-768

Guimarães DO, Borges WS, Vieira NJ, de Oliveira LF, da Silva CH, Lopes NP, Dias LG, Durán-Patrón R, Collado IG, Pupo MT (2010) Diketopiperazines produced by endophytic fungi found in association with two Asteraceae species. Phytochemistry 71:1423-1429

Harman GE, Howell CR, Viterbo A, Chet I, Lorito M (2004) Trichoderma species - opportunistic, avirulent plant symbionts. Nat Rev Microbiol 2:43-56

Hlimi S, Rebuffat S, Goulard C, Duchamp S, Bodo B (1995) Trichorzins HA and MA, antibiotic peptides from Trichoderma harzianum. II. Sequence determination. J Antibiot 48:1254-1261

Hou CT, Ciegler A, Hesseltine CW (1972) New mycotoxin, trichotoxin A, from Trichoderma viride isolated from Southern Leaf Blightinfected corn. Appl Microbiol 23:183-185

Huang Q, Tezuka Y, Kikuchi T, Nishi A, Tubaki K, Tanaka K (1995) Studies on metabolites of mycoparasitic fungi. II. Metabolites of Trichoderma koningii. Chem Pharm Bull 43:223-229

Iida A, Okuda M, Uesato S, Takaishi Y, Shingu T, Morita M, Fujita T (1990) Fungal metabolites. Part 3. Structural elucidation of antibiotic peptides, trichosporin-B-11lb, -1llc, -IVb, -IVc, -IVd, -Vla and -Vlb from Trichoderma polysporum. Application of fast-atom bombardment mass spectrometry/mass spectrometry to peptides containing a unique Aib-Pro peptide bond. J Chem Soc Perkin Trans 1:3249-3255

Iida J, Iida A, Takahashi Y, Takaishi Y, Nagaoka Y, Fujita T (1993) Fungal metabolites. Part 5. Rapid structure elucidation of antibiotic peptides, minor components of trichosporin Bs from Trichoderma polysporum. Application of linked-scan and continuous-flow fastatom bombardment mass spectrometry. J Chem Soc Perkin Trans 1: 357-365

Iida A, Sanekata M, Wada S, Fujita T, Tanaka H, Enoki A, Fuse G, Kanai M, Asami K (1995) Fungal metabolites. XVIII. New membranemodifying peptides, trichorozins I-IV, from the fungus Trichoderma harzianum. Chem Pharm Bull 43:392-397

Iida A, Mihara T, Fujita T, Takaishi Y (1999) Peptidic immunosuppressants from the fungus Trichoderma polysporum. Bioorg Med Chem Lett 9:3393-3396
Ishii T, Nonaka K, Suga T, Ōmura S, Shiomi K (2013) Cytosporone S with antimicrobial activity, isolated from the fungus Trichoderma sp. FKI-6626. Bioorg Med Chem Lett 23:679-681

Iwatsuki M, Kinoshita Y, Niitsuma M, Hashida J, Mori M, Ishiyama A, Namatame M, Nishihara-Tsukashima A, Nonaka K, Masuma R, Otoguro K, Yamada H, Shiomi K, Ōmura S (2010) Antitrypanosomal peptaibiotics, trichosporins B-VIIa and B-VIIb, produced by Trichoderma polysporum FKI-4452. J Antibiot 63: 331-333

Jaklitsch WM (2009) European species of Hypocrea Part I. The greenspores species. Stud Mycol 63:1-91

Jaklitsch WM (2011) European species of Hypocrea part II: species with hyaline ascospores. Fungal Divers 48:1-250

Jaklitsch WM, Voglmayr H (2012) Hypocrea britdaniae and H. foliicola: two remarkable new European species. Mycologia 104:925-941

Jaklitsch WM, Stadler M, Voglmayr H (2012) Blue pigment in Hypocrea caerulescens sp. nov. and two additional new species in sect. Trichoderma. Mycologia 104:1213-1221

Jaklitsch WM, Samuels GJ, Ismaiel A, Voglmayr H (2013) Disentangling the Trichoderma viridescens complex. Persoonia 31:112-146

Jaworski A, Brückner H (1999) Detection of new sequences of peptaibol antibiotics trichotoxins A-40 by on-line liquid chromatographyelectrospray ionization mass spectrometry. J Chromatography A 862:179-189

Jaworski A, Brückner H (2001a) Peptaibol antibiotics trichoaureocins from the mold Trichoderma aureoviride. Amino Acids 21:6-7

Jaworski A, Brückner H (2001b) Sequences of polypeptide antibiotics stilboflavins, natural peptaibol libraries of the mold Stilbella flavipes. J Pept Sci 7:433-447

Jaworski A, Kirschbaum J, Brückner H (1999) Structures of trichovirins II, peptaibol antibiotics from the mold Trichoderma viride NRRL 5243. J Pept Sci 5:341-351

Jeleń H, Błaszczyk L, Chełkowski J, Rogowicz K, Strakowska J (2013) Formation of 6-n-pentyl-2H-pyran-2-one (6-PAP) and other volatiles by different Trichoderma species. Mycol Prog. doi:10.1007/ s11557-013-0942-2

Kim CS, Shirouzu T, Nakagiri A, Sotome K, Nagasawa E, Maekawa N (2012) Trichoderma mienum sp. nov., isolated from mushroom farms in Japan. Antonie van Leeuwenhoek 102:629-641

Kim CS, Shirouzu T, Nakagiri A, Sotome K, Nagasawa E, Maekawa N (2013) Trichoderma eijii and T. pseudolacteum, two new species from Japan. Mycol Prog 12:739-753

Kimonyo A, Brückner H (2013) Sequences of metanicins, 20-residue peptaibols from the ascomycetous fungus CBS 597.80. Chem Biodivers 10:813-826

Kirschbaum J, Krause C, Winzheimer RK, Brückner H (2003) Sequences of alamethicins F30 and F50 reconsidered and reconciled. J Pept Sci 9:799-809

Krause C, Kirschbaum J, Brückner H (2006a) Peptaibiomics: an advanced, rapid and selective analysis of peptaibiotics/peptaibols by SPE/LC-ES-MS. Amino Acids 30:435-443

Krause C, Kirschbaum J, Jung G, Brückner H (2006b) Sequence diversity of the peptaibol antibiotic suzukacillin-A from the mold Trichoderma viride. J Pept Sci 12:321-327

Krause C, Kirschbaum J, Brückner H (2007) Peptaibiomics: microheterogeneity, dynamics, and sequences of trichobrachins, peptaibiotics from Trichoderma parceramosum Bissett (T. longibrachiatum Rifai). Chem Biodivers 4:1083-1102

Kremer A, Li SM (2010) A tyrosine $O$-prenyltransferase catalyses the first pathway-specific step in the biosynthesis of sirodesmin PL. Microbiology 156:278-286

Kubicek CP, Herrera-Estrella A, Seidl-Seiboth V, Martinez DA, Druzhinina IS, Thon M, Zeilinger S, Casas-Flores S, Horwitz BA, Mukherjee PK, Mukherjee M, Kredics L, Alcaraz LD, Aerts A, Antal Z, Atanasova L, Cervantes-Badillo MG, Challacombe J, Chertkov O, McCluskey K, Coulpier F, Deshpande N, von 
Döhren H, Ebbole DJ, Esquivel-Naranjo EU, Fekete E, Flipphi M, Glaser F, Gómez-Rodríguez EY, Gruber S, Han C, Henrissat B, Hermosa R, Hernández-Oñate M, Karaffa L, Kosti I, Le Crom S, Lindquist E, Lucas S, Lübeck M, Lübeck PS, Margeot A, Metz B, Misra M, Nevalainen H, Omann M, Packer N, Perrone G, UrestiRivera EE, Salamov A, Schmoll M, Seiboth B, Shapiro H, Sukno S, Tamayo-Ramos JA, Tisch D, Wiest A, Wilkinson HH, Zhang M, Coutinho PM, Kenerley CM, Monte E, Baker SE, Grigoriev IV (2011) Comparative genome sequence analysis underscores mycoparasitism as the ancestral life style of Trichoderma. Genome Biol 12:R40

Kuhls K, Lieckfeldt E, Samuels GJ, Kovacs W, Meyer W, Petrini O, Gams W, Börner T, Kubicek CP (1996) Molecular evidence that the asexual industrial fungus Trichoderma reese $i$ is a clonal derivative of the ascomycete Hypocrea jecorina. Proc Natl Acad Sci USA 95: $7755-7760$

Laatsch H (2013) Antibase 2013 SciDex v. 1.2.470 - The Natural Compounds Identifier. Wiley-VCH, Weinheim

Lehr N-A, Meffert A, Antelo L, Sterner O, Anke H, Weber RWS (2006) Antiamoebins, myrocin B and the basis of antifungal antibiosis in the coprophilus fungus Stilbella erythrocephala (syn. S. fimetaria). FEMS Microbiol Ecol 55:106-112

Li Q-R, Tan P, Yiang Y-L, Hyde KD, Mckenzie EHC, Bahkali AH, Kang J-C, Wang Y (2013) A novel Trichoderma species isolated from soil in Guizhou, T. guizhouense. Mycol Prog 12:167-172

Lieckfeldt E, Samuels GJ, Nirenberg HI, Petrini O (1999) A morphological and molecular perspective of Trichoderma viride: is it one or two species? Appl Environ Microbiol 65:2418-2428

Loguercio LL, Santos JS, Niella GR, Miranda RAC, de Souza JT, Collins RT, Pomella AWV (2009) Canopy-microclimate effects on the antagonism between Trichoderma stromaticum and Moniliophthora perniciosa in shaded cacao. Plant Pathol 58:11041115

López-Quintero CA, Atanasova L, Franco-Molano AE, Gams W, Komon-Zelazowska M, Theelen B, Müller WH, Boekhout T, Druzhinina I (2013) DNA barcoding survey of Trichoderma diversity in soil and litter of the Colombian lowland Amazonian rainforest reveals Trichoderma strigosellum sp. nov. and other species. Antonie van Leeuwenhoek 104:657-674

Lorito M, Farkas V, Rebuffat S, Bodo B, Kubicek CP (1996) Cell wall synthesis is a major target of mycoparasitic antagonism by Trichoderma harzianum. J Bacteriol 178:6382-6385

Lu X, Tian L, Chen G, Xu Y, Wang HF, Li ZQ, Pei YH (2012) Three new compounds from the marine-derived fungus Trichoderma atroviride G20-12. J Asian Nat Prod Res 14:647-651

Maddau L, Cabras A, Franceschini A, Linaldeddu BT, Crobu S, Roggio T, Pagnozzi D (2009) Occurrence and characterization of peptaibols from Trichoderma citrinoviride, an endophytic fungus of cork oak, using electrospray ionization quadrupole time-of-flight mass spectrometry. Microbiology 155:3371-3381

Matsuura K, Yesilada A, Iida A, Takaishi Y, Kanai M, Fujita T (1993) Fungal metabolites. Part 8. Primary structures of antibiotic peptides, hypelcin A-I, A-Il, A-III, A-IV, A-V, A-VI, A-VII, AVIII and A-IX from Hypocrea peltata. J Chem Soc, Perkin Trans 1:381-387

Matsuura K, Shima O, Takeda Y, Takaishi Y, Nagaoka Y, Fujita T (1994) Fungal metabolites. XV. Primary structures of antibiotic peptides, hypelcins B-I, B-II, B-III, B-IV and B-V, from Hypocrea peltata. Application of electrospray mass spectrometry and electrospray mass spectrometry/mass spectrometry. Chem Pharm Bull 42: 1063-1069

Mattinen ML, Lantto R, Selinheimo E, Kruus K, Buchert J (2008) Oxidation of peptides and proteins by Trichoderma reesei and Agaricus bisporus tyrosinases. J Biotechnol 133:395-402

Medeiros FHV, Pomella AWV, de Souza JT, Niella GR, Valle R, Bateman RP, Fravel D, Vinyard B, Hebbar PK (2010) A novel, integrated method for management of witches' broom disease in cacao in Bahia, Brazil. Crop Prot 29:704-711

Mikkola R, Andersson MA, Kredics L, Grigoriev PA, Sundell N, Salkinoja-Salonen MS (2012) 20-residue and 11-residue peptaibols from the fungus Trichoderma longibrachiatum are synergistic in forming $\mathrm{Na}^{+} / \mathrm{K}^{+}$-permeable channels and adverse action towards mammalian cells. FEBS J 279:4172-4190

Mohamed-Benkada M, Montagu M, Biard JF, Mondeguer F, Vérité P, Dalgalarrondo M, Bissett J, Pouchus YF (2006) New short peptaibols from a marine Trichoderma strain. Rapid Commun Mass Spectrom 20:1176-1180

Mukherjee PK, Wiest A, Ruiz N, Keightley A, Moran-Diez ME, McCluskey K, Pouchus YF, Kenerley CM (2011) Two classes of new peptaibols are synthesized by a single non-ribosomal peptide synthetase of Trichoderma virens. J Biol Chem 286: $4544-4554$

Neuhof T, Dieckmann R, Druzhinina IS, Kubicek CP, von Döhren H (2007) Intact-cell MALDI-TOF mass spectrometry analysis of peptaibol formation by the genus TrichodermalHypocrea: can molecular phylogeny of species predict peptaibol structures? Microbiology 153:3417-3437

New AP, Eckers C, Haskins NJ, Neville WA, Elson S, Hueso-Rodríguez JA, Rivera-Sagredo A (1996) Structures of polysporins A-D, four new peptaibols isolated from Trichoderma polysporum. Tetrahedron Lett 37:3039-3042

Nielsen KF, Månsson M, Rank C, Frisvad JC, Larsen TO (2011) Dereplication of microbial natural products by LC-DAD-TOFMS. J Nat Prod 74:2338-2348

Oh S-U, Yun B-S, Lee S-J, Yoo I-D (2005) Structures and biological activities of novel antibiotic peptaibols neoatroviridins A-D from Trichoderma atroviride. J Microbiol Biotechnol 15:384-387

Overton BE, Stewart EL, Geiser DM, Jaklitsch WM (2006a) Systematics of Hypocrea citrina and related taxa. Stud Mycol 56:1-38

Overton BE, Stewart EL, Geiser DM (2006b) Taxonomy and phylogenetic relationships of nine species of Hypocrea with anamorphs assignable to Trichoderma section Hypocreanum. Stud Mycol 56: 39-65

Panizel I, Yarden O, Ilan M, Carmeli S (2013) Eight new peptaibols from sponge-associated Trichoderma atroviride. Mar Drugs 11:49374960

Pócsfalvi G, Scala F, Lorito M, Ritieni A, Randazzo G, Ferranti P, Vékey K, Maloni A (1998) Microheterogeneity characterization of a trichorzianine-A mixture from Trichoderma harzianum. J Mass Spectrom 33:154-163

Pomella AWV, de Souza JT, Niella GR, Bateman RP, Hebbar PK, Loguercio LL, Lumsden DR (2007) Trichoderma stromaticum for management of witches' broom in Brazil. In: Vincent C, Goettel MS, Lazarovits G (eds) Biological Control: a global perspective. CABI International, Wallingford, pp 210-217

Przybylski M, Dietrich I, Manz I, Brückner H (1984) Elucidation of structure and microheterogeneity of the polypeptide antibiotics paracelsin and trichotoxin A-50 by fast atom bombardment mass spectrometry in combination with selective in situ hydrolysis. Biomed Mass Spectrom 11:569-582

Psurek A, Neusüß C, Degenkolb T, Brückner H, Balaguer E, Imhof D, Scriba GKE (2006) Detection of new amino acid sequences of alamethicins F30 by nonaqueous capillary electrophoresis-mass spectrometry. J Pept Sci 12:279-290

Réblová M, Seifert KA (2004) Cryptadelphia (Trichosphaeriales), a new genus for holomorphs with Brachysporium anamorphs and clarification of the taxonomic status of Wallrothiella. Mycologia 96:343367

Rebuffat S, el Hajji M, Hennig P, Davoust D, Bodo B (1989) Isolation, sequence, and conformation of seven trichorzianines B from Trichoderma harzianum. Int J Pept Protein Res 34:200 210 
Rebuffat S, Prigent Y, Auvin-Guette C, Bodo B (1991) Tricholongins BI and BII, 19-residue peptaibols from Trichoderma longibrachiatum. Solution structure from two-dimensional NMR spectroscopy. Eur J Biochem 201:661-674

Rebuffat S, Conraux L, Massias M, Auvin-Guette C, Bodo B (1993) Sequence and solution conformation of the 20-residue peptaibols, saturnisporins SA II and SA IV. Int J Pept Prot Res 41:74-84

Reino JL, Guerrero RF, Hernández-Galán R, Collado IG (2008) Secondary metabolites from species of the biocontrol agent Trichoderma. Phytochem Rev 7:89-123

Ren J, Xue C, Tian L, Xu M, Chen J, Deng Z, Proksch P, Lin W (2009) Asperelines $\mathrm{A}-\mathrm{F}$, peptaibols from the marine-derived fungus Trichoderma asperellum. J Nat Prod 72:1036-1044

Ren J, Yang Y, Liu D, Chen W, Proksch P, Shao B, Lin W (2013) Sequential determination of new peptaibols asperelines $\mathrm{G}_{-} \mathrm{Z}_{12}$ produced by marine-derived fungus Trichoderma asperellum using ultrahigh pressure liquid chromatography combined with electrospray-ionization tandem mass spectrometry. J Chromatogr A 1309:90-95

Rifai MA (1969) A revision of the genus Trichoderma. Mycol Pap 116:1-56

Ritieni A, Fogliano V, Nanno D, Randazzo G, Altomare C, Perrone G, Bottalico A, Maddau L, Marras F (1995) Paracelsin E, a new peptaibol from Trichoderma saturnisporum. J Nat Prod 58:17451748

Röhrich CR, Iversen A, Jaklitsch WM, Voglmayr H, Berg A, Dörfelt H, Thrane U, Vilcinskas A, Nielsen KF, von Döhren H, Brückner H, Degenkolb T (2012) Hypopulvins, novel peptaibiotics from the polyporicolous fungus Hypocrea pulvinata, are produced during infection of its natural hosts. Fungal Biol 116:1219-1231

Röhrich CR, Iversen A, Jaklitsch WM, Voglmayr H, Vilcinskas A, Nielsen KF, Thrane U, von Döhren H, Brückner H, Degenkolb T (2013a) Screening the biosphere: the fungicolous fungus Trichoderma phellinicola, a prolific source of hypophellins, new 17-, 18-, 19-, and 20-residue peptaibiotics. Chem Biodivers 10:787-812

Röhrich CR, Vilcinskas A, Brückner H, Degenkolb T (2013b) The sequences of the eleven-residue peptaibiotics: suzukacillins-B. Chem Biodivers 10:827-837

Rossman AY, Seifert KA, Samuels GJ, Minnis AM, Schroers H-J, Lombard L, Crous PW, Põldmaa K, Cannon PF, Summerbell RC, Geiser DM, Zhuang W-Y, Hirooka Y, Herrera C, Salgado-Salazar C, Chaverri P (2013) Genera in Bionectriaceae, Hypocreaceae, and Nectriaceae (Hypocreales) proposed for acceptance or rejection. IMA Fungus 4:41-51

Ruiz N, Wielgosz-Collin G, Poirier L, Grovel O, Petit KE, MohamedBenkada M, du Pont TR, Bissett J, Vérité P, Barnathan G, Pouchus YF (2007) New Trichobrachins, 11-residue peptaibols from a marine strain of Trichoderma longibrachiatum. Peptides 28:1351-1358

Samuels GJ, Ismaiel A (2011) Hypocrea peltata: a mycological Dr Jekyll and Mr Hyde? Mycologia 103:616-630

Samuels GJ, Lieckfeldt E, Nirenberg HI (1999) Trichoderma asperellum, a new species with warted conidia, and redescription of $T$. viride. Sydowia 51:71-88

Samuels GJ, Dodd SL, Lu B-S, Petrini O, Schroers H-J, Druzhinina IS (2006) The Trichoderma koningii aggregate species. Stud Mycol 56: $67-133$

Samuels GJ, Ismaiel A, de Souza J, Chaverri P (2012a) Trichoderma stromaticum and its overseas relatives. Mycol Prog 11:215-254

Samuels GJ, Ismaiel A, Mulaw TB, Szakacs G, Druzhinina IS, Kubicek CP, Jaklitsch WM (2012b) The Longibrachiatum clade of Trichoderma: a revision with new species. Fungal Divers 55:77-108

Schirmböck M, Lorito M, Wang Y-L, Hayes CK, Arisan-Atac I, Scala F, Harman GE, Kubicek CP (1994) Parallel formation and synergism of hydrolytic enzymes and peptaibols antibiotics, molecular mechanisms involved in the antagonistic action of Trichoderma harzianum against phytopathogenic fungi. Appl Environ Microbiol 60:4364-4370

Selinheimo E, NiEidhin D, Steffensen C, Nielsen J, Lomascolo A, Halaouli S, Record E, O'Beirne D, Buchert J, Kruus K (2007) Comparison of the characteristics of fungal and plant tyrosinases. J Biotechnol 130:471-478

Shi M, Chen L, Wang X-W, Zhang T, Zhao P-B, Song X-Y, Sun C-Y, Chen X-L, Zhou B-C, Zhang Y-Z (2012) Antimicrobial peptaibols from Trichoderma pseudokoningii induce programmed cell death in plant fungal pathogens. Microbiology 158:166-175

Stoppacher N, Reithner B, Omann M, Zeilinger S, Krska R, Schuhmacher R (2007) Profiling of trichorzianines in culture samples of Trichoderma atroviride by liquid chromatography/tandem mass spectrometry. Rapid Commun Mass Spectrom 21:3963-3970

Stoppacher N, Zeilinger S, Omann M, Lassahn PG, Roitinger A, Krska R, Schuhmacher R (2008) Characterisation of the peptaibiome of the biocontrol fungus Trichoderma atroviride by liquid chromatography/tandem mass spectrometry. Rapid Commun Mass Spectrom 22:1889-1898

Stoppacher N, Neumann NK, Burgstaller L, Zeilinger S, Degenkolb T, Brückner H, Schuhmacher R (2013) The comprehensive peptaibiotics database. Chem Biodivers 10:734-743

Vinale F, Sivasithamparam K, Ghisalberti EL, Marra R, Barbetti MJ, Li H, Woo SL, Lorito M (2008a) A novel role for Trichoderma secondary metabolites in the interactions with plants. Physiol Physiol Mol Plant Pathol 72:80-86

Vinale F, Sivasithamparam K, Ghisalberti EL, Marra R, Woo SL, Lorito M (2008b) Trichoderma-plant-pathogen interactions. Soil Biol Biochem 40:1-10

Viterbo A, Wiest A, Brotman Y, Chet I, Kenerley C (2007) The 18mer peptaibols from Trichoderma virens elicit plant defence responses. Mol Plant Pathol 8:737-746

Vizcaíno JA, Cardoza RE, Dubost L, Bodo B, Gutiérrez S, Monte E (2006) Detection of peptaibols and partial cloning of a putative peptaibol synthetase gene from Trichoderma harzianum CECT 2413. Folia Microbiol 51:114-120

Wada S-I, Nishimura T, Iida A, Toyama N, Fujita T (1994) Primary structures of antibiotic peptides, trichocellins-A and $-\mathrm{B}$, from Trichoderma viride. Tetrahedron Lett 35:3095-3098

Wada S-I, Iida A, Akimoto N, Kanai M, Toyama N, Fujita T (1995) Fungal metabolites. XIX. Structural elucidation of channel-forming peptides, trichorovins-I-XIV, from the fungus Trichoderma viride. Chem Pharm Bull 43:910-915

Wiest A, Grzegowski D, Xu B-W, Goulard C, Rebuffat S, Ebbole DJ, Bodo B, Kenerley C (2002) Identification of peptaibols from Trichoderma virens and cloning of a peptaibol synthetase. J Biol Chem 277:20862-20868

Xie Z-L, Li H-J, Wang L-Y, Liang W-L, Liu W, Lan W-J (2013) Trichodermaerin, a new diterpenoid lactone from the marine fungus Trichoderma erinaceum associated with the sea star Acanthaster planci. Nat Prod Commun 8:67-68

Yabuki T, Miyazaki K, Okuda T (2014) Japanese species of the Longibrachiatum clade of Trichoderma. Mycoscience 55:196212

Yamaguchi K, Tsurumi Y, Suzuki R, Chuaseeharonnachai C, SriIndrasutdhi V, Boonyuen N, Okane I, Suzuki KI, Nakagiri A (2012) Trichoderma matsushimae and T. aeroaquaticum: two aeroaquatic species with Pseudaegerita-like propagules. Mycologia 104: $1109-1120$

Zou HX, Xie X, Zheng XD, Li SM (2011) The tyrosine $O$ prenyltransferase $\operatorname{SirD}$ catalyzes $O-, N-$, and $C$-prenylations. Appl Microbiol Biotechnol 89:1443-1451 